\title{
Plasma phospholipidomic profile differs between children with phenylketonuria and healthy children
}

Inês M. S. Guerra ${ }^{a}$, Luísa Diogo ${ }^{b}$, Marisa Pinhoc, Tânia Meloa,d, Pedro Domingues $^{a}$, M. Rosário Domingues ${ }^{a, d}$, Ana S. P.Moreira ${ }^{a, e,}{ }^{*}$

a Mass Spectrometry Center, LAQV-REQUIMTE, Department of Chemistry, University of Aveiro, Campus Universitário de Santiago, 3810-193 Aveiro, Portugal

${ }^{b}$ Reference Center of Inherited Metabolic Diseases, Hospital Pediátrico, Centro Hospitalar e Universitário de Coimbra, 3000-075 Coimbra, Portugal

c ECOMARE, CESAM - Center for Environmental and Marine Studies, Department of Biology, University of Aveiro, Campus de Santiago, 3810-193 Aveiro, Portugal

dCESAM - Centre for Environmental and Marine Studies, Department of Chemistry, University of Aveiro, Campus Universitário de Santiago, 3810-193 Aveiro, Portugal

e CICECO - Aveiro Institute of Materials, Department of Chemistry, University of Aveiro, Campus Universitário de Santiago, 3810-193 Aveiro, Portugal

${ }^{*}$ Corresponding author. E-mail address: ana.moreira@ua.pt 


\begin{abstract}
Phenylketonuria (PKU) is a disease of the catabolism of phenylalanine (Phe), caused by an impaired function of the enzyme phenylalanine hydroxylase. Therapeutics is based on the restriction of Phe intake, which mostly requires a modification of the diet. Dietary restrictions can lead to imbalances in specific nutrients, including lipids. In the present study, the plasma phospholipidome of PKU and healthy children (CT) was analysed by HILIC-MS/MS and GC-MS. Using this approach, 187 lipid species belonging to 9 different phospholipid classes and 3 ceramides were identified. Principal component analysis of the lipid species dataset showed a distinction between PKU and CT groups. Univariate analysis revealed that 146 species of phospholipids were significantly different between both groups. Lipid species showing significant variation included phosphatidylcholines, containing polyunsaturated fatty acids (PUFA), which were more abundant in PKU. The high level of PUFA-containing lipid species in children with PKU may be related to a diet supplemented with PUFA. This study was the first report comparing the plasma polar lipidome of PKU and healthy children, highlighting that the phospholipidome of PKU children is significantly altered compared to CT. However, further studies with larger cohorts are needed to clarify whether these changes are specific to phenylketonuric children.
\end{abstract}

Keywords: Inborn errors of metabolism; phenylketonuria; plasma; phospholipids; lipidomics; mass spectrometry. 


\section{Introduction}

Phenylketonuria (PKU) is the most prevalent inborn error in amino acid metabolism ${ }^{1-3}$. PKU is characterized by an impaired activity of the enzyme phenylalanine hydroxylase (PAH), resulting in a complete or partial inability of the enzyme to convert L-phenylalanine (Phe) to L-tyrosine. Deficiency of the PAH enzyme results in increased levels of $P$ he in the blood (hyperphenylalaninemia) 4-6. The accumulation of Phe can lead to intellectual impairment, microcephaly, seizures, and motor deficits ${ }^{2,7,8}$. Early diagnosis through neonatal screening and rapid therapeutic implementation are essential to prevent these possible complications ${ }^{9}$. The therapeutic approach for PKU is based on a lifelong Pherestricted diet, with a low intake of natural proteins ${ }^{1}$.

In the low-Phe diet, protein-rich foods like eggs, fish, meat and dairy products, which are the main natural dietary sources of long-chain polyunsaturated fatty acids (PUFA), are excluded ${ }^{10}$. Thus, to provide the required amount of daily protein intake, PKU patients consume commercial formulas with Phe-free essential amino acids, as well containing vitamins, minerals, and other nutrients ${ }^{11}$. To ensure that the essential PUFA dietary requirements are met, amino acid formulas containing PUFA and PUFA supplements are used together with PKU diet ${ }^{12}$. Despite the use of amino acid formulas and PUFA supplements, as well as some special low-protein foods available to PKU patients, high dietary restrictions can lead to nutritional imbalances, notably in lipids.

Alterations in blood lipids, especially in serum and plasma lipoprotein components, have already been described in PKU patients on a Phe-restricted diet $^{3}$. Statistically significant lower levels of total cholesterol (TC), low-density lipoprotein cholesterol (LDL-C) and high-density lipoprotein cholesterol (HDL-C) were observed in PKU patients compared to healthy subjects ${ }^{5,13-16}$. However, no statistical difference in the levels of TC, LDL-C and HDL-C has been reported in other studies ${ }^{14,17}$, highlighting the existence of dissimilar results in the plasma lipid profile of PKU patients.

Moreover, previous studies have revealed changes in the fatty acid (FA) profile of plasma and red blood cell (RBC) samples from PKU patients ${ }^{3}$. The existing literature is ambiguous about the prevalence of long-chain PUFA 
deficiency in patients with PKU. However, some studies have shown a significant decrease in important PUFA, such as docosahexaenoic acid (DHA, 22:6n-3), eicosapentaenoic acid (EPA, 20:5n-3) and arachidonic acid (AA, 20:4n-6), in patients with PKU who maintained a Phe-restricted diet (with no information available on PUFA supplementation) ${ }^{18-22}$. These reduced levels have been associated with dietary restrictions ${ }^{22}$, as PKU patients do not consume foods of animal origin rich in PUFA ${ }^{2,3,23}$. The low dietary intake of long-chain PUFA is thought to be the main cause of the decrease in the levels of DHA, EPA and AA, as their endogenous synthesis is very low 24,25 .

Given the important role of long-chain PUFA for the normal cognitive and visual development, controlled trials were also performed to elucidate the effect of PUFA supplementation on the FA status of patients with PKU, using plasma or RBC samples ${ }^{4,23,26-31}$. Although some conflicting results between studies were reported, in most cases an increase in the content of $n$-3 PUFA was observed ${ }^{3}$.

Since FA are mainly esterified in other classes of lipids, namely in phospholipids (PL) which contain about $50 \%$ of the total amount of plasma $\mathrm{FA}^{32}$, variations in the plasma FA profile of PKU patients may impact these classes. Some of the studies that have shown variations in the FA profile of PKU individuals have been performed using the plasma PL fraction 4,20,21,23,29,33. However, changes at the level of individual PL species in PKU patients have never been explored.

Since PL have an important role in the signalling and regulatory functions in health and disease ${ }^{3}$, further characterization of plasma PL in PKU patients is needed to identify the plasticity of the PL profile due to dietary restrictions.

The present study represents the first report comparing the plasma phospholipidome of children with PKU and healthy children (control group, CT), highlighting the differences in the lipid profile of children with PKU at the level of PL species. For that, the PL plasma extracts obtained from children with PKU and healthy children (CT) were characterized by hydrophilic interaction liquid chromatography-tandem mass spectrometry (HILIC-MS/MS) for the identification of polar lipid species. Complementarily, gas chromatography-mass spectrometry (GC-MS) analysis was carried out for the determination of the composition of FA. 


\section{Material and Methods}

\subsection{Study Design Overview}

Plasma samples were obtained from PKU children $(n=15)$ between 3 and 17 years old, followed at the Centro de Referência de Doenças Hereditárias do Metabolismo - Centro Hospitalar Universitário de Coimbra (Coimbra, Portugal). With an average of 9 years of age, the studied group included 7 females and 8 males. Patients were on a lifelong Phe-restricted diet, prescribed with Phe-free essential amino acid formulas (13 patients) and one of two types of PUFA supplements: KeyOmega ${ }^{\circledR}$ (Vitaflo) powdered blend of $200 \mathrm{mg} \mathrm{AA}$ and $100 \mathrm{mg}$ DHA per sachet (3 patients), or DHA Richoil ${ }^{\mathrm{TM}}$ (D.M.F. Dietetic Metabolic Food SRL) containing $250 \mathrm{mg}$ of DHA per capsule (3 patients), according to Phe tolerance and PUFA plasma levels. At the time of the study, all patients, except one, had genetic studies completed. p.R261Q in five alleles, p.R270K in four and p.R158Q in three, were the most common pathogenic variations found. No correlation between phenotype and genotype was established. Summary information on patients is shown in Supplementary Table S1. For the controls (CT, $n=12$ ), recruited among those submitted to blood collection for other causes (e.g., minor surgery procedures) and in good general health and normal diet, the age of the CT children varied between 7 and 16 years. With an average of 12 years of age, the CT group included 4 females and 8 males. The collection of the blood samples was taken in the fasted state. Blood $(2 \mathrm{~mL})$ was collected into lithium-heparin tubes and centrifuged $(2000 \times \mathrm{g}, 10 \mathrm{~min})$ to recover the plasma fraction. The plasma samples, after collection, were stored at $-80^{\circ} \mathrm{C}$ until the lipid extraction.

The collection of plasma samples required for this study was accepted by the Hospital Ethics Committee (vote number: CHUC-094-16) and all parents (or legal representatives) signed informed consent, in agreement with the ethical standards of the Declaration of Helsinki. 


\subsection{Plasma Phospholipids Extraction}

The PL were extracted from plasma samples by solid-phase extraction (SPE) with a Visiprep SPE vacuum Manifold (Supelco, Sigma-Aldrich, Bellefonte, PA, USA) ${ }^{34,35}$. Briefly, protein precipitation was performed by mixing $100 \mu \mathrm{L}$ of plasma sample with $900 \mu \mathrm{L}$ of acetonitrile (ACN) with $1 \%$ formic acid, followed by vortexing (30 s) and centrifugation ( $626 \times \mathrm{g}, 5 \mathrm{~min})$. The resulting supernatant was transferred to a SPE column (HybridSPE-Phospholipid $30 \mathrm{mg}$, SUPELCO, Sigma-Aldrich, Bellefonte, PA, USA), after conditioning step (1 $\mathrm{mL}$ of ACN). As most supernatant was eluted, the column was washed with $1 \mathrm{~mL}$ of $\mathrm{ACN}$ with $1 \%$ formic acid and $1 \mathrm{~mL}$ of $A C N$. The PL were then eluted with ACN with $5 \%$ aqueous ammonia $(2 \times 1 \mathrm{~mL})$. The $\mathrm{PL}$ were recovered and dried under a nitrogen stream. The extracts were then dissolved in dichloromethane and filtered using a HAMILTON glass syringe and syringe filter $(0.22 \mu \mathrm{m}$ pore size, $4 \mathrm{~mm}$ diameter, Millex-GV Durapore $\AA^{(P V D F)}$ membrane, hydrophilic, Millipore Corporation, Billerica, MA, USA). The filtered samples were collected in amber vials, dried and stored at $-80 \stackrel{\circ}{\mathrm{C}}$ until further lipid analysis.

\subsection{Phospholipids Quantification}

After SPE extraction, the total amount of PL was quantified by phosphorus (P) measurement ${ }^{36}$, as previously done ${ }^{34,37}$. PL-enriched extracts were dissolved in $100 \mu \mathrm{L}$ of dichloromethane, and a volume of $10 \mu \mathrm{L}$ was transferred, to a glass tube previously washed with $5 \%$ nitric acid, in duplicate. After drying the solvent under a stream of nitrogen, $125 \mu \mathrm{L}$ of $70 \%$ perchloric acid were added to each tube. Samples were incubated in a heat block (Stuart, Staffordshire, U.K.) for $1 \mathrm{~h}$ at $180^{\circ} \mathrm{C}$, followed by cooling to room temperature. After that, $825 \mu \mathrm{L}$ of Milli-Q water, $125 \mu \mathrm{L}$ of ammonium molybdate (20 mM prepared in Milli-Q water), and $125 \mu \mathrm{L}$ of ascorbic acid (567 mM prepared in Milli-Q water) were added to each sample, being vortexed between each addition. Samples were then placed during $10 \mathrm{~min}$ at $100^{\circ} \mathrm{C}$ in a water bath. Afterwards, using a cold-water bath, the samples were cooled down. The absorbance was measured at $797 \mathrm{~nm}$ in a Multiskan GO1.00.38 Microplate Spectrophotometer (Thermo Scientific, Hudson, 
$\mathrm{NH}$, USA) controlled by SkanlT software, version 3.2 (Thermo Scientific). The P content of each extract was calculated from a calibration curve prepared by carrying out the same procedure (without the heating block step) with standards containing up to $2 \mu \mathrm{g}$ of $\mathrm{P}$ obtainedfrom a sodium dihydrogen phosphate dihydrate solution (100 $\mu \mathrm{g} \mathrm{mL}^{-1}$ of $\left.\mathrm{P}\right)$. The total amount of $\mathrm{PL}$ was then estimated by multiplying the amount of $\mathrm{P}$ by $25^{38}$.

2.4. Characterization of Fatty Acids Profile by Gas Chromatography Coupled to Mass Spectrometry (GC-MS)

FA analysis was performed by GC-MS after transmethylation of PL-enriched extracts ${ }^{39}$, as routinely used in authors' laboratory ${ }^{35,37}$. Briefly, an amount of lipid extract equivalent to $15 \mu \mathrm{g}$ of total $\mathrm{PL}$ was dissolved in a volume of $1 \mathrm{~mL}$ of internal standard methyl nonadecanoate (Sigma, St. Louis, MO, USA) prepared in $n$-hexane $(3.63 \mu \mathrm{M})$. FA were converted to fatty acid methyl esters (FAME) by adding $200 \mu \mathrm{L}$ of methanolic $\mathrm{KOH}$ solution $(2 \mathrm{M})$ and intense vortex-mixing for 1 $2 \mathrm{~min}$. Thereafter, $2 \mathrm{~mL}$ of $\mathrm{NaCl}$ solution ( $171 \mathrm{mM}$ ) were added, being centrifuged at $626 \times \mathrm{g}$ for $5 \mathrm{~min}$. A volume of $600 \mu \mathrm{L}$ of the organic phase was then collected and dried under a nitrogen stream. The resulting FAME derivatives were dissolved in $100 \mu \mathrm{L}$ of $n$-hexane and $2 \mu \mathrm{L}$ were then used for GC-MS analysis (Agilent Technologies 8860 GC System, Santa Clara, CA, USA). The GC equipment was connected to an Agilent 5977B Mass Selective Detector operating with an electron impact mode at $70 \mathrm{eV}$ and scanning the range $m / z 50$ 550 in a $1 \mathrm{~s}$ cycle in a full scan mode acquisition. The oven temperature was programmed from an initial temperature of $58^{\circ} \mathrm{C}$ for $2 \mathrm{~min}$, a linear increase to $160^{\circ} \mathrm{C}$ at $25^{\circ} \mathrm{C} \mathrm{min}^{-1}$, followed by a linear increase at $2{ }^{\circ} \mathrm{C} \mathrm{min}-1$ to $210^{\circ} \mathrm{C}$, then at $20^{\circ} \mathrm{C} \mathrm{min}-1$ to $225^{\circ} \mathrm{C}$, standing at $225^{\circ} \mathrm{C}$ for $15 \mathrm{~min}$. The injector and detector temperatures were 220 and $230^{\circ} \mathrm{C}$, respectively. Helium was used as the carrier gas at a flow rate of $1.4 \mathrm{ml} \mathrm{min}^{-1}$. The data acquisition software used was GCMS5977B/Enhanced MassHunter. The acquired data were analysed using the software Agilent MassHunter Qualitative Analysis 10.0. FA identification was 
achieved by MS spectrum comparison with the chemical database NIST library and "The Lipid Web" ${ }^{40}$, and take into account the retention times and MS spectra of FAME standards (Supelco 37 Component FAME Mix, Sigma-Aldrich, Darmstadt, Germany). FA quantification was conducted using calibration curves obtained from FAME standards under the same instrumental conditions.

2.5. Characterization of the Phospholipid Profile by Hydrophilic Interaction Liquid Chromatography Coupled to High-Resolution Tandem Mass Spectrometry (HILIC-MS/MS)

PL-enriched extracts were analysed by HILIC-MS using a highperformance liquid chromatography (HPLC) system (Ultimate 3000 Dionex, Thermo Fisher Scientific, Bremen, Germany) with an autosampler coupled online to the Q-Exactive $\AA$ hybrid quadrupole Orbitrap $\AA$ mass spectrometer (Thermo Fisher Scientific, Waltham, MA, USA) ${ }^{34,35}$. The mobile phases were as follow: mobile phase A [ACN/MeOH/water 50:25:25 (v/v/v) with $5 \mathrm{mM}$ ammonium acetate] and mobile phase $B$ [ACN/MeOH 60:40 (v/v) with $5 \mathrm{mM}$ ammonium acetate]. Initially, $5 \%$ of mobile phase $A$ was held isocratically for $2 \mathrm{~min}$, followed by successive linear increases to $70 \%$ of $A$ within $11 \mathrm{~min}$, and then to $90 \%$ of $A$ in $7 \mathrm{~min}$. The solvent $(90 \%$ of $A)$ was held isocratically during $30 \mathrm{~min}$, returning to the initial conditions in $5 \mathrm{~min}$, followed by a $5 \mathrm{~min}$ re-equilibration period prior next injection. In a glass vial with a micro-insert, a volume of $5 \mu \mathrm{L}$ of each PLenriched extract, previously resuspended in dichloromethane $\left(1 \mu \mathrm{g} \mathrm{L}^{-1} \mathrm{PL}\right)$, was mixed with an aliquot of $4 \mu \mathrm{L}$ of a mixture of PL standards (Avanti Polar Lipids, Inc., Alabaster, AL; $0.02 \mu \mathrm{g}$ of dimyristoyl phosphatidylcholine, $0.02 \mu \mathrm{g}$ of dimyristoyl phosphatidylethanolamine, $0.012 \mathrm{\mu g}$ of dimyristoyl phosphatidylglycerol, $0.04 \mu \mathrm{g}$ of dimyristoyl phosphatidylserine) and $91 \mu \mathrm{L}$ of starting eluent system ( $95 \%$ of eluent B and $5 \%$ of eluent A). A volume of $5 \mu \mathrm{L}$ of this mixture was then introduced into the ACE $\Theta$ HILIC-N column $(100 \mathrm{~mm} \times 1$ $\mathrm{mm}, 3 \mu \mathrm{m}$ ) with a flow rate of $50 \mu \mathrm{L} \mathrm{min}{ }^{-1}$. The column oven temperature was maintained at $35 \stackrel{\circ}{\circ}$. The mass spectrometer with Orbitrap technology was 
operated in a positive/negative switching toggles between positive (electrospray voltage of $3.0 \mathrm{kV}$ ) and negative (electrospray voltage of $-2.7 \mathrm{kV}$ ) ion modes with a sheath gas flow of $15 \mathrm{U}$ and a capillary temperature of $250^{\circ} \mathrm{C}$. A top-10 datadependent method was used. Acquisition cycles consisted of one full scan mass spectrum, with a resolution of 70,000, automatic gain control (AGC) target of $1 \times$ $10^{6}$, and ten data-dependent MS/MS scans with a resolution of 17,500 and AGC target of $1 \times 10^{5}$, that were repeated continuously through the experiments with a dynamic exclusion of $60 \mathrm{~s}$ and $2 \times 10^{4}$ of threshold intensity. MS/MS were acquired using a stepped normalized collisional energy of 25, 30, and $35 \mathrm{eV}$. Data acquisition was performed using the Xcalibur data system (V3.3, Thermo Fisher Scientific, USA). The MZmine 2.32 software ${ }^{41}$ was used for filtering LC-MS raw data, peak detection, peak processing, and assignment against an in-house database. Only peaks with an intensity higher than $1 \times 10^{4}$ were considered. The validated peaks were within the typical retention time $(R T)$ of the respective lipid class and exact mass accuracy with an error of less than $5 \mathrm{ppm}$. The identification of the most lipid species was further validated by analysis of the MS/MS data, allowing to confirm polar head group and find the fatty acyl chain(s) for most of the molecular species. The normalization of the LC-MS data was performed by exporting the integrated peak areas of the extracted ion chromatograms and dividing the peak area of each species by the peak area of the lipid standard with the closest RT.

\subsection{Statistical Analysis}

Multivariate and univariate statistical analyses were performed using $R$ version 3.6.2 42 in Rstudio version 1.2.5 ${ }^{43}$. The $R$ package Metaboanalyst was used for imputation and log transformation of the HILIC-MS data (lipid species) and GC-MS data (fatty acids) ${ }^{44}$. EigenMS was also used for normalization of LCMS data ${ }^{45}$. The $R$ built-in function and the $R$ package pcaMethods were used to perform principal component analysis (PCA) ${ }^{46}$. Shapiro-Wilk test followed by Welch t-test (for variables with normal distribution) or Mann-Whitney (for variables 
with non-normal distribution) were performed with $\mathrm{R}$ built-in functions. P-values were corrected for multiple testing using Benjamin-Hochberg method (with $R$ built-in function) for the false discovery rate (FDR, $q$-values) ${ }^{47}$. Heatmaps were created from autoscaled data using the $R$ package pheatmap ${ }^{48}$, and using "Euclidean" as clustering distance, and "ward.D" as the clustering method. All graphics and boxplots were created using the R packages ggplot2 ${ }^{49}$, plyr ${ }^{50}$, dplyr ${ }^{51}$, tidyr ${ }^{52}$ and ggrepe $\left.\right|^{53}$.

\section{Results}

\subsection{Phospholipids quantification}

The total amount of PL recovered after SPE (expressed in $\mu \mathrm{g}$ PL per 100 $\mu \mathrm{L}$ of plasma; mean \pm standard deviation) was $41.27 \pm 7.30$ and $53.78 \pm 21.73$ for PKU and CT samples, respectively. No statistically significant differences were found by univariate analysis between the two groups ( $q$ value $>0.05$ ).

\subsection{Fatty Acid Composition analysis by GC-MS}

For an overview of the composition of esterified FA, GC-MS analysis was performed. A total of 9 FA were identified in the PKU and CT groups (Table 1). Palmitic acid (16:0) was the most abundant lipid in both groups $(30.75 \pm 6.94$ in PKU and $22.91 \pm 7.48$ in CT), followed by stearic acid (18:0) (18.80 \pm 4.92 in PKU and $13.09 \pm 3.77$ in CT) and linoleic acid (LA, 18:2 n-6) (17.74 \pm 4.62 in PKU and $12.21 \pm 6.73$ in CT). 
Table 1. Fatty acid (FA) profile of extracts enriched in phospholipids (PL) obtained from plasma samples of phenylketonuric (PKU) and healthy children (control, CT), determined by GC-MS. The data represents mean values of $\mathrm{FA}$ in $\mu \mathrm{g}$ per $100 \mu \mathrm{g} \mathrm{PL} \pm$ standard deviations.

\begin{tabular}{lll}
\hline Fatty acids & PKU & CT \\
\hline $14: 0$ & $1.45 \pm 0.32$ & $1.08 \pm 0.34$ \\
\hline $16: 0$ & $30.75 \pm 6.94$ & $22.91 \pm 7.48$ \\
\hline $18: 0$ & $18.80 \pm 4.92$ & $13.09 \pm 3.77$ \\
\hline $18: 1 n-9$ & $13.04 \pm 2.81$ & $8.09 \pm 2.24$ \\
\hline $18: 1$ & $4.24 \pm 0.47$ & $3.55 \pm 0.25$ \\
\hline $18: 2 n-6$ & $17.74 \pm 4.62$ & $12.21 \pm 6.73$ \\
\hline $20: 4 n-6$ & $10.40 \pm 3.31$ & $7.76 \pm 3.12$ \\
\hline $20: 5 n-3$ & $2.81 \pm 0.35$ & $2.58 \pm 0.11$ \\
\hline $22: 6 n-3$ & $5.37 \pm 1.14$ & $4.17 \pm 1.14$ \\
\hline
\end{tabular}

Multivariate principal component analysis (PCA) analysis was achieved using the FA data set. The PCA score plot of the two first dimensions (Dim) showed that the two groups were not differentiated, with the model capturing $84.7 \%$ of the total variance in the data set (Dim 1: $75.4 \%$; and $\operatorname{Dim} 2: 9.3 \%$ ) (Figure 1).

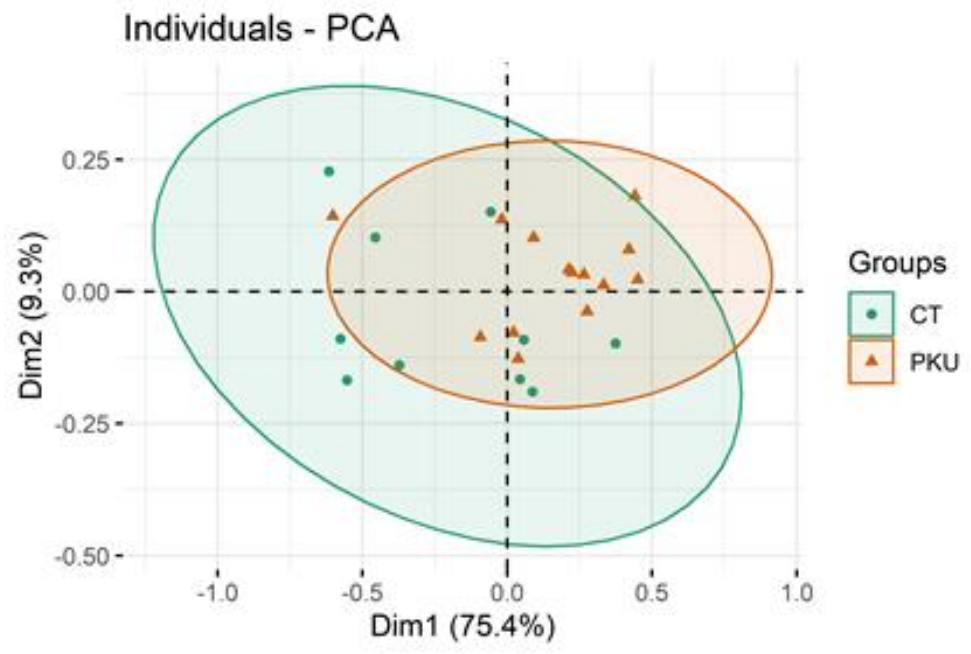

Figure 1. Principal component analysis (PCA) score plot of the fatty acids data set obtained by GC-MS analysis of phospholipid-enriched extracts obtained from plasma samples of phenylketonuric (PKU) and healthy children (control, CT). 
Univariate analysis (Shapiro-Wilk test followed by Welch $t$-test or MannWhitney test) was used to assess the existence of significant differences in the FA composition by comparing the two groups (CT vs PKU). Of the 9 FA identified, 6 showed significant differences between groups, with higher content in children with PKU when compared to the CT group (Figure 2, Supplementary Table S2). The most significant increases were observed in oleic acid (18:1n-9) ( $q$-value < 0.01 ), followed by myristic acid (14:0), stearic acid (18:0), EPA and DHA ( $q$-value $<0.05)$. No statistical difference was observed for palmitic acid (16:0), LA, and AA.

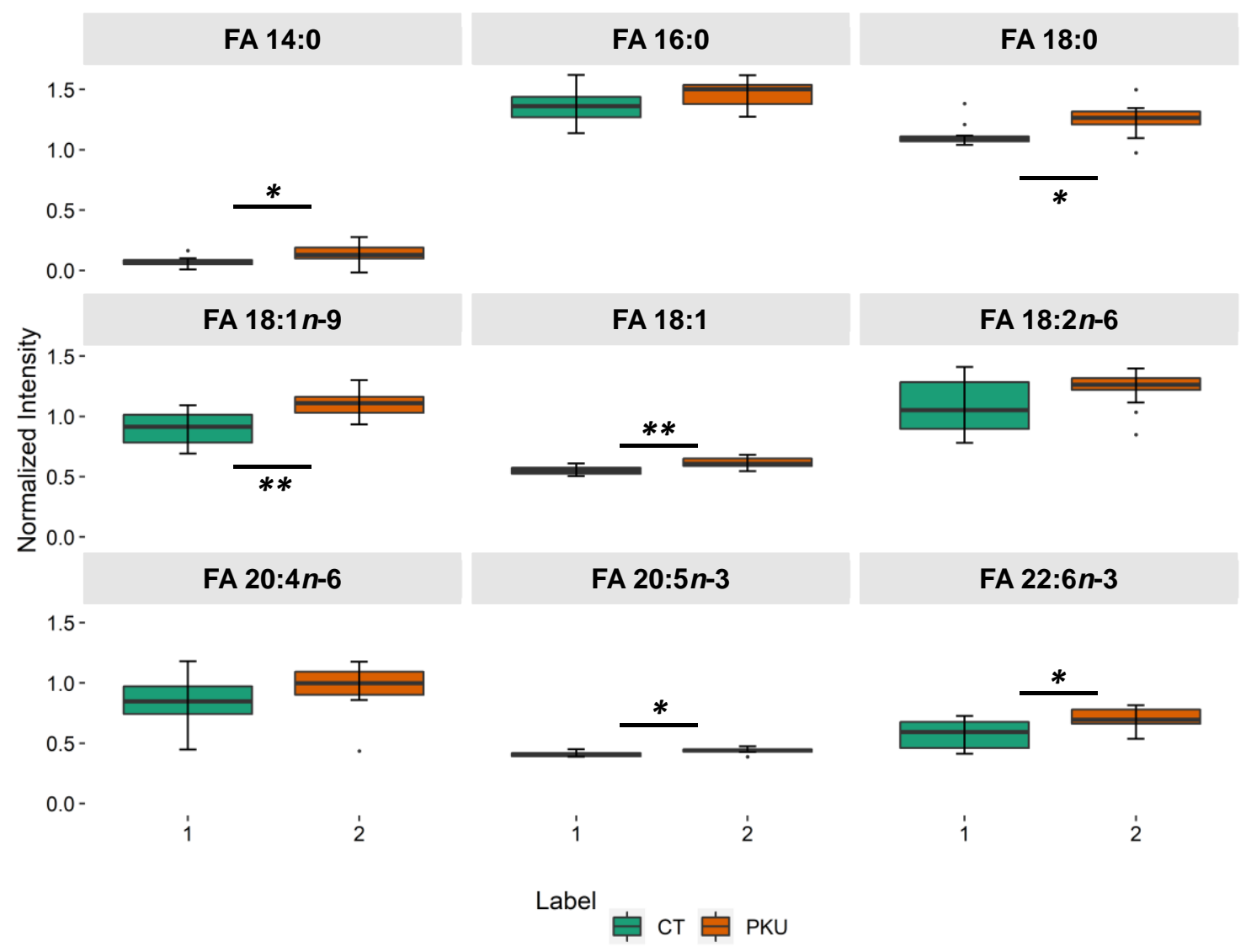

Figure 2. Boxplots of the fatty acids (FA) identified by GC-MS from control (CT) and phenylketonuric (PKU) children organized (left to right, top to bottom) by increasing number of carbon atoms and double bonds. FA are labelled as follows: FA xx:i ( $x x=$ number of carbon atoms; $i=$ number of double bonds), followed by $n-y$ for unsaturated FA ( $y$ =double-bond position related to the methyl end). Data from FA quantification were glog transformed using Metaboanalyst ${ }^{44}$. Significant differences between the groups revealed by Welch ttest or Mann-Whitney test are identified by horizontal lines and marked with * if $q<0.05$ and ** if $q<0.01$ (Supplementary Table S2). 


\subsection{Identification of the phospholipid profile by HILIC-MS/MS}

The plasma phospholipid profile of the two experimental groups (PKU and CT) was characterized using high-resolution HILIC-MS/MS. In total, we identified 187 species of $\mathrm{PL}(\mathrm{m} / \mathrm{z}$ values), belonging to 9 different classes: phosphatidylcholine (PC; including diacyl, alkyl/alkenyl-acyl and oxidized species), lyso PC (LPC; including monoacyl, alkyl/alkenyl and oxidized species), sphingomyelin (SM), phosphatidylethanolamine (PE; including diacyl, alkyl/alkenyl-acyl and oxidized species), lyso PE (LPE), phosphatidylglycerol (PG), lyso PG (LPG), phosphatidylinositol (PI), and phosphatidylserine (PS). In addition to the PL species, 3 species of sphingolipids belonging to the class of ceramides (Cer) have also been identified (Supplementary Table S3). The PC, LPC, SM and Cer species were identified and semi-quantified in the positive mode as $[\mathrm{M}+\mathrm{H}]^{+}$ions.. Confirmation of the PC, LPC and SM classes were obtained by analysing the MS/MS data of $[\mathrm{M}+\mathrm{H}]^{+}$ions with the identification of the product ion of exact mass 184.0739 , corresponding to the phosphocholine polar head (Figure S1a and S2a). The FA composition of the PC and LPC species was determined, from the negative mode $\mathrm{MS} / \mathrm{MS}$ data of the $\left[\mathrm{M}+\mathrm{CH}_{3} \mathrm{COO}\right]^{-}$ions, by identifying the product ions corresponding to the fatty acyl chains such as [RCOO]- (Figure S1b). Distinctly from PC and LPC which have even $\mathrm{m} / \mathrm{z}$ values, $\mathrm{SM}$ have odd $\mathrm{m} / \mathrm{z}$ values. Also, the MS/MS spectra of $[\mathrm{M}+\mathrm{H}]^{+}$ions of $\mathrm{SM}$ showed product ions of the sphingoid base chain, allowing the sphingoid base and FA amide substituent to be deduced (Figure S2a). Confirmation of SM species was also obtained by the identification in the $\mathrm{MS} / \mathrm{MS}$ spectra of $\left[\mathrm{M}+\mathrm{CH}_{3} \mathrm{COO}\right]^{-}$ions of the product ion at $m / z 168.0425$, corresponding to the phosphocholine polar head without a methyl group, and observing the characteristic neutral loss of $74 \mathrm{Da}$, corresponding to the loss of methyl acetate (Figure S2b). The MS/MS fragmentations of the sphingoid base of Cer, in the positive mode as $[\mathrm{M}+\mathrm{H}]^{+}$ions, allowed to confirm the identification of the respective sphingoid base and the FA amide substituent (Figure S3).

PE, LPE, PG, LPG, PI, and PS species were identified and semi-quantified in the negative mode as $[\mathrm{M}-\mathrm{H}]$ ] ions. Confirmation of the phospholipid class for 
the PE and LPE species was obtained, from MS/MS data in the positive mode, of $[\mathrm{M}+\mathrm{H}]^{+}$ions, by identifying the typical neutral loss of $141 \mathrm{Da}$, corresponding to the polar head of phosphoethanolamine (Figure S4a). The product ion at $m / z$ 171.0058, corresponding to the glycerol phosphate anion in the MS/MS spectra of the $[\mathrm{M}-\mathrm{H}]^{-}$ions of $P G$ and $L P G$ species that allow these classes of phospholipids to be confirmed, was not visible due to the low intensity of the respective molecular ions (Figure S5). These species were identified based on the retention time $(\mathrm{RT})$ and exact mass measurements. Confirmation of the phospholipid class for $\mathrm{PI}$ species, in the negative mode as $[\mathrm{M}-\mathrm{H}]^{-}$ions, was obtained by identifying the product ion at $m / z 241.0113$, corresponding to the inositol head group (Figure S6). The FA composition of PE, LPE, PG, LPG and $\mathrm{PI}$ was confirmed, in the MS/MS spectra of the $[\mathrm{M}-\mathrm{H}]^{-}$ions, by identification of the product ions corresponding to the fatty acyl chains such as [RCOO]. The identification of the PS species was only based on the mass accuracy (error $<5$ ppm) and RT. As an example, MS/MS spectra of isomeric plasmanyl and plasmenyl species, as well as an oxidized PL species are also shown in the Supplementary (Figures S7 and S8).

To visualize sample grouping, the multivariate analysis by PCA was performed on the lipid species data set. Two identified outliers, from the PKU and CT group, were removed from further analysis. The PCA score plot of the lipid species demonstrated that the two groups were separated in the first two dimensions, and the model captured $62.9 \%$ of the total variance (Dim1: $51.2 \%$; and Dim2: 11.7\%) (Figure 3). The two groups (CT and PKU) were separated along Dim1, the main discriminating component, with the CT group located at negative values of Dim1 and the PKU group located at positive values of Dim1 (Figure 3). 


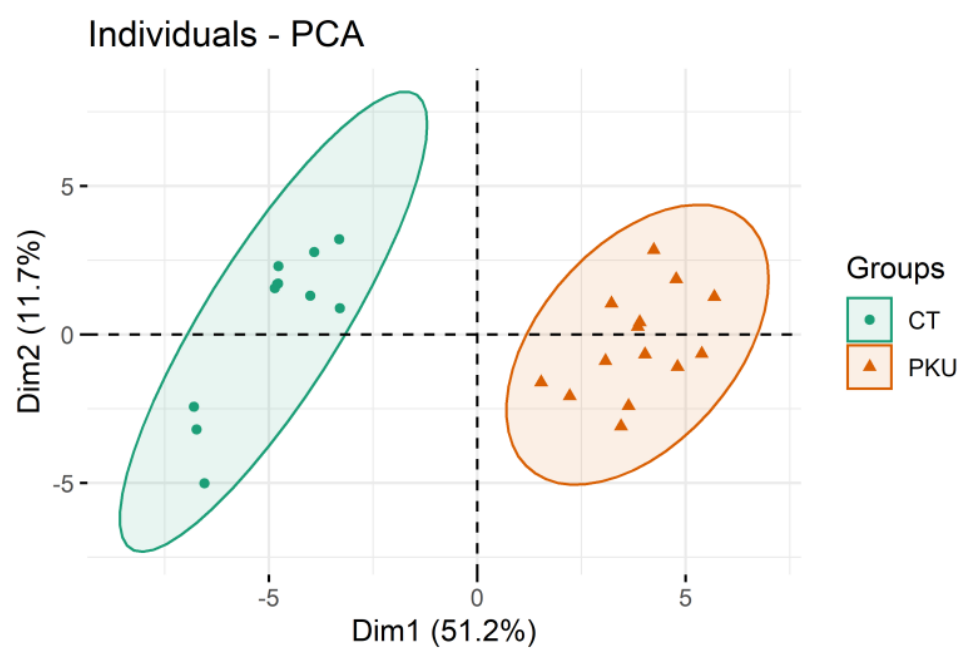

Figure 3. Principal component analysis (PCA) score plot of the lipid species dataset obtained by HILIC$\mathrm{MS} / \mathrm{MS}$ analysis of phospholipid-enriched extracts obtained from plasma samples of phenylketonuric (PKU) and healthy (control, CT) children.

Univariate analysis (Shapiro-Wilk test followed by Welch $t$-test or MannWhitney test) was also performed to evaluate lipid species with significant variation between the two groups (CT vs PKU). The results revealed that 146 of 190 lipid species were statistically different between groups ( $q$-value $<0.05$ ) (Supplementary Table S4). Boxplots of the 16 main species with the lowest $q$ values $(q$-value $<0.001)$ are shown in Figure 4. These 16 species that exhibited major variation included 7 PC, 5 SM, 3 PS, and 1 LPC. All of these PC species $(40: 8,44: 12,42: 7,40: 7,44: 11,42: 9$ and 40:5) were significantly increased in PKU children compared to CT individuals. Also, LPC (14:0) and SM (d34:1, d36:3, d36:2, d34:2, and d38:3) showed the same trend as that observed in PC species. In contrast, PS species (38:4, 40:6, and 38:6) were significantly reduced in PKU individuals. It was possible to identify the FA composition of 4 of the 16 species, namely PC (40:8) identified as PC (20:4/20:4), PC (42:7) identified as PC (20:1/22:6), PC (40:7) identified as PC (18:1/22:6), and SM (d34:1) identified as SM (d18:1/16:0). 


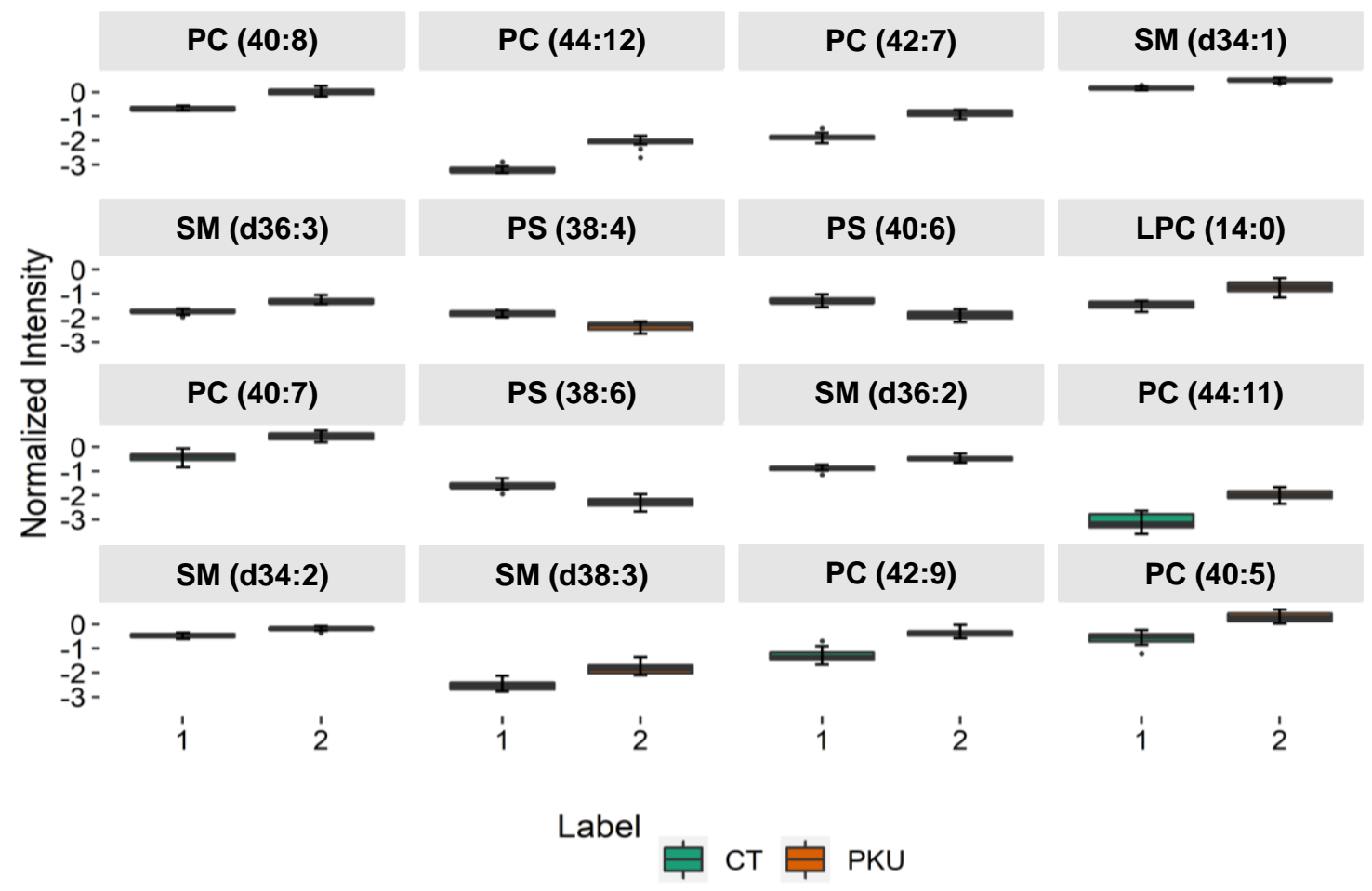

Figure 4. Boxplots of the 16 main lipid species showing the major variation between control (CT) and phenylketonuric (PKU) children sorted (left to right, top to bottom) by the lower $q$-values of the Welch t-test or Mann-Whitney test (Supplementary Table S4). Data were glog transformed after missing value imputation using Metaboanalyst ${ }^{44}$ and normalized with EigenMS ${ }^{45}$. All phospholipid species displayed in the figure showed a $q$-value $<0.001$ after Benjamin-Hochberg correction for the false discovery rate (FDR). The phospholipid species are labelled as follows: $A A A A(x x: i)$ (AAAA=lipid class abbreviation; $x x=n u m b e r$ of carbon atoms in fatty acid(s); i=number of double bonds). Abbreviations of the lipid classes: LPC, lysophosphatidylcholine;PC, phosphatidylcholine; PS, phosphatidylserine; SM, sphingomyelin.

A heatmap (double dendrograms) with two-dimensional hierarchical clustering was created using the top $25 q$-values ( $q$-value $<0.001)$ from Welch $t$ test or Mann-Whitney test (Figure 5). In the first level of the upper hierarchical dendrogram, it is possible to observe that the samples were clustered independently into two groups: one cluster for the CT group, and another for the PKU group. The separation of the CT group from the PKU group was coherent with what was shown in the PCA score plot (Figure 3). In respect to the clustering of individual lipid species by similarity in changes in lipid expression, the first group at the first level of the dendrogram (on the left of the heatmap in Figure 5) included 1 SM (d32:2) and 3 PS (38:4, 40:6 and 38:6), which were more abundant in the CT group. The second group included 13 PC, 5 SM, 1 LPC, and 2 PI species, which were more abundant in the PKU group. Concerning the 
composition of these top 25 species, PC species with high total carbon chain length (C38-44) and level of unsaturation (4-12), bearing PUFA, were more abundant in the PKU individuals.

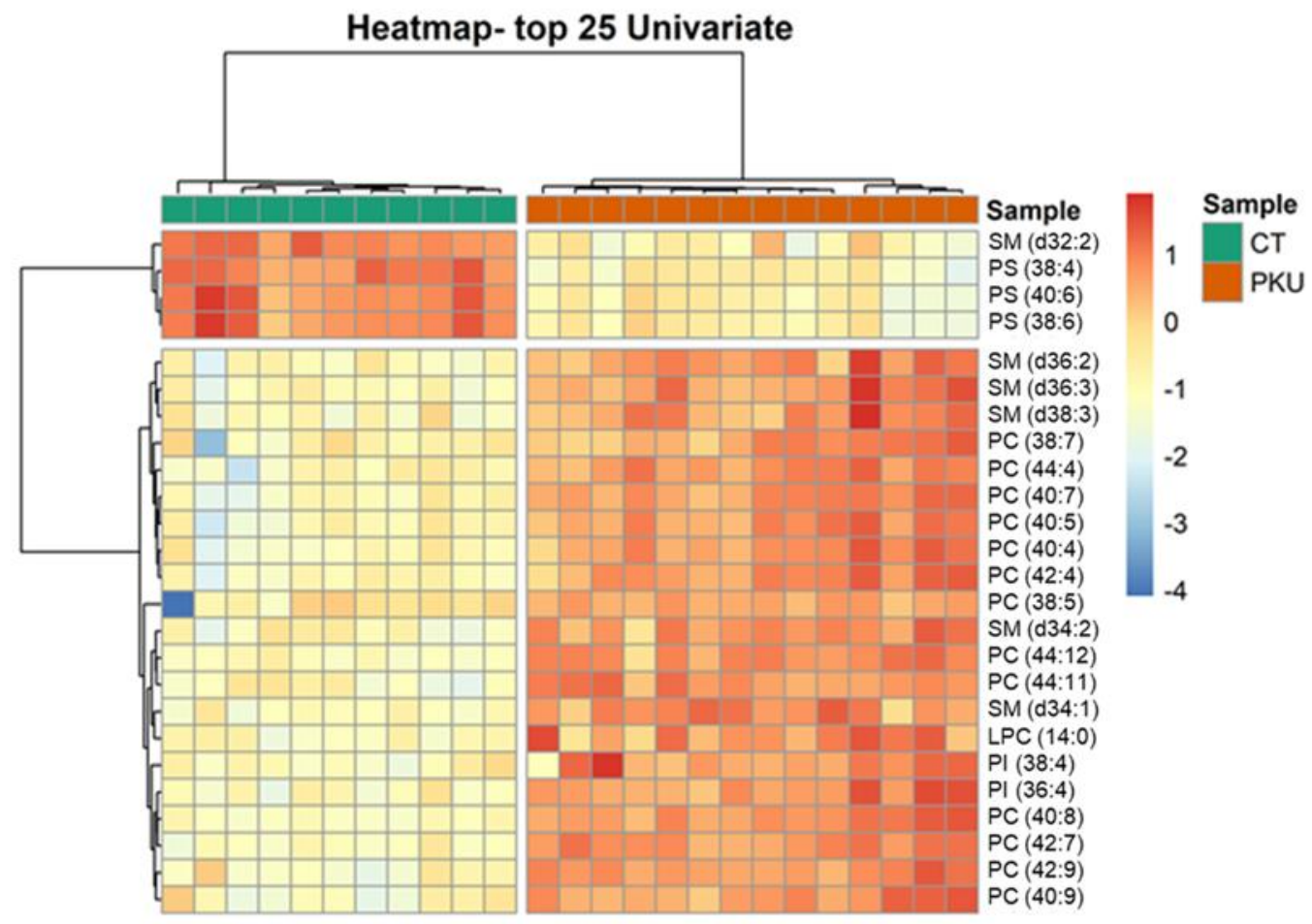

Figure 5. Two-dimensional hierarchical clustering heatmap of the 25 main lipid species with the lowest $q$ values of the Welch t-test or Mann-Whitney test. The dendrogram at the top shows the clustering of the samples, and on the left shows the clustering of the lipid species. Levels of relative abundance are shown on the colour scale, with numbers indicating the fold difference from the mean. Phospholipid species are indicated as follows: $A A A A(x x: i)(A A A A=$ lipid class; $x x=$ number of carbon atoms in fatty acid(s); i=number of double bonds). Abbreviations of the lipid classes: LPC, lysophosphatidylcholine; PC, phosphatidylcholine; PI, phosphatidylinositol; PS, phosphatidylserine; SM, sphingomyelin.

\section{Discussion}

Previous studies have revealed alterations in lipoprotein levels of serum/plasma and the FA profile of plasma and red blood cells of PKU individuals $3,5,16,19,26,29,33,54,55$. Such changes can affect the composition of PL as they are the main components of human plasma lipoproteins and incorporate FA into their composition ${ }^{56}$. Indeed, some of the changes reported in the FA profile of PKU individuals have been found in the plasma PL fraction 4,20,21,23,29,33. To our knowledge, this study represents the first report comparing plasma 
phospholipidome of PKU children and healthy children, highlighting the changes in the lipid profiles of PKU children at the level of individual lipid species.

Initially, by a complete analysis of the FA composition of the plasma PL fraction, a total of 9 FA was identified. The profile of FA identified is consistent with the profile previously reported in the literature for the plasma/serum PL fraction, including 16:0 and FA with 18 carbon chains as highly abundant FA 35,57 . In accordance to the multivariate analysis of the FA dataset by PCA (Figure 1), the PKU and CT groups were not separated.

Regarding to the univariate analysis of the FA dataset, the PKU group showed a significant increase in the level of PUFA DHA and EPA, compared to the CT group (Figure 2). Consistent with these results, in seven studies ${ }^{4,23,26-}$ 29,58, higher levels of DHA in the total serum/plasma PL fraction were observed in PKU individuals supplemented with PUFA. Only two of these seven studies showed an increase in the level of EPA in plasma ${ }^{23,28}$, as observed in this study. It is known that in healthy individuals only $2-5 \%$ and $5-10 \%$ of $\alpha$-linolenic acid are converted to DHA and EPA, respectively ${ }^{59}$. Consequently, the DHA and EPA status is determined by food intake ${ }^{60}$. As PKU individuals do not consume the typical food sources of DHA, such as fish, the increase in DHA level in PKU patients taking supplements/amino acid mixtures with DHA could be a consequence of such DHA supplementation. However, it is known that dietary DHA causes a dose-dependent, and saturable increase in plasma DHA level and modest increases in EPA. DHA itself can serve as a substrate for metabolic retroconversion to EPA through a $\beta$-oxidation reaction ${ }^{61}$. Such a reaction may also have contributed to the increased level of EPA in PKU patients with DHA supplementation. The levels of AA were not significantly different between PKU and CT groups, which is consistent with other studies $4,28,29$.

Overall, the effect of long-chain PUFA supplements on the FA profile of PKU patients reveals an increase in the content of $n-3$ PUFA ${ }^{3}$, especially DHA and EPA, as observed in this study. Such an increase can have positive effects on the health of PKU patients. It is well known that PUFAs are important structural and functional constituents of all cell membranes and are crucial for the normal visual and cognitive development ${ }^{24,62}$. Also, DHA and EPA have been associated with anti-inflammatory properties ${ }^{63,64}$. The increase in DHA and EPA promotes 
the increased generation of anti-inflammatory cytokines and the generation of special pro-resolving lipid mediators, such as resolvins, protectins and maresins 63. Therefore, it is possible to speculate that DHA supplementation would result in an increased capability to produce special pro-resolving lipid mediators and a decrease in the inflammatory state. Such an anti-inflammatory action may be relevant, considering that a pro-inflammatory state has already been described in patients with PKU 24,65. Furthermore, the higher levels of $n-3$ PUFA are associated with a reduction in the risk of developing cardiovascular diseases and atherosclerosis $62,63,66,67$. Despite the health benefits associated with consuming PUFA, particularly $n-3$ PUFA, it should be noted that the question about the dosage of PUFA needed to achieve optimal effects has remained unanswered.

The PCA of the lipid species showed a separation between the PKU and CT groups (Figure 3), highlighting the importance of the study at the level of the lipid species. The results of the univariate analysis (Figure 4 and 5) revealed a significant increase in the PC, SM and PI species and a decrease of PS species in the PKU group.

Lipid species of the PC class, the PL class most abundant in biological membranes and in plasma lipoproteins ${ }^{56,68}$, showed a significant increase in PKU children compared to CT. Thirteen PC species were in the top 25 lipid species with a major variation. Although the composition of FA was only identified for 6 of them, it was possible to deduce that the remaining $7 \mathrm{PC}$ species also contain PUFA in their composition. The increased number of plasmatic $P C$ bearing longchain PUFA in PKU children may be a consequence of their daily PUFA supplementation.

Beyond the common diacyl PC, also an up-regulation of some ether PC as well as ether PE has been observed in PKU children, both representing 15.06\% of all statistically significant lipid species (Supporting Information, Table S4). The physiological functions of these unique alkyl-acyl PLs are not fully understood. However, it has been reported that ether-linked PL, especially plasmalogens, have antioxidant properties because of their ability to scavenge oxygen radicals, as they are preferentially oxidized ${ }^{69-71}$, and seem to be transformed into inoffensive products that can be reutilized by the organism ${ }^{71,72}$. The increase of 
some ether-like PC and PE may be beneficial for PKU children because they can decrease oxidative stress and lipid peroxidation ${ }^{3}$.

Regarding the increase of PI species, namely PI (36:4) and PI (38:4), observed in $\mathrm{PKU}$ children, it is known that $\mathrm{PI}$ species influence the structure and function of plasma lipoproteins, but their role in plasma is unclear and requires further investigation ${ }^{73}$. Alterations in PI content are probably associated with their signalling roles, as they are important precursors of signalling molecules, such as PIPs that regulate metabolic processes ${ }^{74}$. Therefore, we speculate that the observed increase in PI species could be associated with a decrease in its phosphorylation to phosphoinositides, by phosphatidylinositol kinases (e.g. phosphatidylinositol 3-kinase), due to the reduction in oxidative stress ${ }^{75}$.

$\mathrm{PS}$ is the major class of anionic phospholipids in eukaryotic membranes ${ }^{76}$. The decrease in their levels in the PKU group, namely of PS (38:4), PS (38:6) and PS (40:6), may occur due to the increased biosynthesis of PC, because mammalian cells produce PS by exchanging the headgroup for serine ${ }^{76}$. It should be noted that the full function of plasma PS is not yet known, and their downregulation is not clearly understood. However, the PS class, at the cellular level, has been associated with anti-inflammatory roles ${ }^{77}$. In the future, it is important to study the roles of this class in the plasma.

$\mathrm{SM}$ is the most abundant class of sphingolipids in lipoproteins, constituting about $20 \%$ of total plasma PL. This class of lipids can be hydrolysed by the action of sphingomyelinase, giving rise to Cer, which by the action of sphingomyelin synthase are again converted to SM. Our study reports a significant increase of $6 \mathrm{SM}$ in the plasma of PKU children, compared to the CT group. Previous studies have reported that higher plasma levels of SM are associated with increased atherosclerosis and risk factors for coronary heart disease in adults ${ }^{78}$. Consequently, in the future, it is necessary to clarify the variation and the significance of elevated levels of this class of lipids in children with PKU.

The lipidomic approaches used here revealed alterations in the PL profile of PKU patients. Such alterations could have clinical application for monitoring the disease and possible comorbidities, as well as therapeutic response. Nonetheless, we recognize that the strength of our results is limited, namely by the small sample size and the variable diet and supplementation in the PKU 
group. Additionally, the quality of PUFA supplementation taken by the patients might influence the PKU lipidomic profile. However, this first study is important to give new clues for subsequent studies taking into account the prevalence of PKU (a rare disease) and the specific study population, children (among whom it might be quite difficult to obtain samples for research analysis). In further studies, it should be interesting to evaluate the alterations in the plasma lipid profiles with the type of diet and supplementation practiced by the PKU patients. These constraints should be considered in order to better understand how the lipid profile of phenylketonuric is modified, as well as to analyse alterations in possible metabolic pathways. For example, the amino acid restriction, necessary in PKU, could influence the function of mTOR resulting in alterations in lipolysis/lipogenesis ${ }^{79,80}$. Also, a longitudinal analysis is needed to assess the overall progression of changes in the PL profile over time in PKU patients, compared to controls.

\section{Conclusions}

The present study reports, for the first time, the application of mass spectrometry-based lipidomics to identify the plasma phospholipidome of children with phenylketonuria and healthy children. The changes observed in the profile of esterified FA in the PL of PKU children, in particular the increase in the levels of $n-3$ PUFA, namely DHA and EPA, may be associated with PUFA supplementation. In terms of individual PL species, the most significant changes were revealed by increased plasma levels of PC, PI and SM and decreased PS species. In particular, an increase in several PC with PUFA was observed. The increased content of PL species containing PUFA could have a positive impact on reducing the inflammatory state of patients, as well as reducing the risk of developing cardiovascular disease and atherosclerosis. Also, the PKU group showed an increase in ether-like PC and PE, which are associated with antioxidant activity. Regarding the higher levels of SM, it is necessary to clarify the variation and the significance of this class of lipids in children with PKU, as 
they have previously been associated with atherosclerosis and risk factors for coronary heart disease in human adults.

\section{Associated Content}

\section{Supporting Information}

(Table S1) Data collected for each of PKU patients. (Table S2) Significant variations between the FA identified by GC-MS from PKU and CT groups. (Table S3) Phospholipids and sphingolipids identified by HILIC-MS and MS/MS of phospholipid (PL)-enriched extracts obtained from plasma samples collected, in fasting, from PKU patients and healthy controls (mass error $<5$ ppm). (Table S4) The 146 lipid species showing significant variation between PKU and control (CT) groups. (Figure S1) Representative MS/MS spectra of phosphatidylcholine (PC) lipid species. (Figure S2) Representative MS/MS spectra of sphingomyelin (SM) lipid species. (Figure S3) Representative MS/MS spectrum of ceramide (Cer) lipid species. (Figure S4) Representative MS/MS spectra of phosphatidylethanolamine (PE) lipid species. (Figure S5) Representative MS/MS spectrum of phosphatidylglycerol (PG) lipid species. (Figure S6) Representative MS/MS spectrum of phosphatidylglycerol (PI) lipid species. (Figure S7) Representative MS/MS spectra of isomeric plasmanyl (O-) and plasmenyl (P-) phosphatidylcholine (PC) lipid species, eluting at the same retention time in LCMS. (Figure S8) Representative MS/MS spectra of oxidized phosphatidylcholine (PC) lipid species.

\section{Acknowledgments}

Thanks are due to the FCT/MCT (Portugal) for the financial support to CICECO - Aveiro Institute of Materials (UIDB/50011/2020+UIDP/50011/2020), CESAM (UIDB/50017/2020+UIDP/50017/2020), LAQV-REQUIMTE (UIDB/50006/2020), QOPNA (UID/QUI/00062/2019), and RNEM (LISBOA-010145-FEDER-402-022125) through national funds and, where applicable, cofinanced by the FEDER, within the PT2020 Partnership Agreement and Compete 
2020. Ana Moreira thanks the research contract under the project Coccolitho4BioMat - Coccolithophore microalgae biorefinery: an approach for sustainable biomaterials (POCl-01-0145-FEDER-031032), funded by Centro2020, through FEDER and PT2020.Tânia Melo also thanks the research contract under the project Omics4Algae - Lipidomic tools for chemical phenotyping, traceability and valorisation of seaweeds from aquaculture as a sustainable source of high added-value compounds (POCI-01-0145-FEDER030962), funded by Centro2020, through FEDER and PT2020.

\section{References}

(1) van Spronsen, F. J.; van Wegberg, A. M.; Ahring, K.; Bélanger-Quintana, A.; Blau, N.; Bosch, A. M.; Burlina, A.; Campistol, J.; Feillet, F.; Giżewska, M.; Huijbregts, S. C.; Kearney, S.; Leuzzi, V.; Maillot, F.; Muntau, A. C.; Trefz, F. K.; van Rijn, M.; Walter, J. H.; MacDonald, A. Key European Guidelines for the Diagnosis and Management of Patients with Phenylketonuria. The Lancet Diabetes \& Endocrinology 2017, 5 (9), 743756. https://doi.org/10.1016/S2213-8587(16)30320-5.

(2) Drzymała-Czyż, S.; Kałużny, Ł.; Krzyżanowska-Jankowska, P.; Walkowiak, D.; Morzymas, R.; Walkowiak, J. Deficiency of Long-Chain Polyunsaturated Fatty Acids in Phenylketonuria: A Cross-Sectional Study. Acta Biochimica Polonica 2018, 65 (2), 303-308. https://doi.org/10.18388/abp.2018_2565.

(3) Guerra, I. M. S.; Ferreira, H. B.; Neves, B.; Melo, T.; Diogo, L. M.; Domingues, M. R.; Moreira, A. S. P. Lipids and Phenylketonuria: Current Evidences Pointed the Need for Lipidomics Studies. Archives of Biochemistry and Biophysics 2020, 688, 108431. https://doi.org/10.1016/j.abb.2020.108431.

(4) Agostoni, C.; Scaglioni, S.; Bonvissuto, M.; Bruzzese, M. G.; Giovannini, M.; Riva, E. Biochemical Effects of Supplemented Long-Chain Polyunsaturated Fatty Acids in Hyperphenylalaninemia. Prostaglandins, Leukotrienes and Essential Fatty Acids 2001, 64 (2), 111-115. https://doi.org/10.1054/plef.2001.0249.

(5) Couce, M. L.; Vitoria, I.; Aldámiz-Echevarría, L.; Fernández-Marmiesse, A.; Roca, I.; Llarena, M.; Sánchez-Pintos, P.; Leis, R.; Hermida, A. Lipid Profile Status and Other Related Factors in Patients with Hyperphenylalaninaemia. Orphanet Journal of Rare Diseases 2016, 11 (1), 1-12. https://doi.org/10.1186/s13023-016-0508-x. 
(6) Blau, N.; van Spronsen, F. J.; Levy, H. L. Phenylketonuria. The Lancet 2010, 376 (9750), 1417-1427. https://doi.org/10.1016/S01406736(10)60961-0.

(7) Loeber, J. G. Neonatal Screening in Europe; the Situation in 2004. Journal of Inherited Metabolic Disease 2007, 30 (4), 430-438. https://doi.org/10.1007/s10545-007-0644-5.

(8) Enns, G. M.; Koch, R.; Brumm, V.; Blakely, E.; Suter, R.; Jurecki, E. Suboptimal Outcomes in Patients with PKU Treated Early with Diet Alone: Revisiting the Evidence. Molecular Genetics and Metabolism 2010, 101 (2), 99-109. https://doi.org/10.1016/j.ymgme.2010.05.017.

(9) Blau, N.; Hennermann, J. B.; Langenbeck, U.; Lichter-Konecki, U. Diagnosis, Classification, and Genetics of Phenylketonuria and Tetrahydrobiopterin (BH4) Deficiencies. Molecular Genetics and Metabolism 2011, 104, S2-S9. https://doi.org/10.1016/j.ymgme.2011.08.017.

(10) Santos, L. L. dos; Magalhães, M. de C.; Januário, J. N.; Aguiar, M. J. B. de; Carvalho, M. R. S. The Time Has Come: A New Scene for PKU Treatment. Genetics and molecular research: GMR 2006, 5 (1), 33-44.

(11) MacLeod, E. L.; Ney, D. M. Nutritional Management of Phenylketonuria. Annales Nestlé 2010, 68 (2), 58-69. https://doi.org/10.1159/000312813.

(12) van Wegberg, A. M. J.; MacDonald, A.; Ahring, K.; Bélanger-Quintana, A.; Blau, N.; Bosch, A. M.; Burlina, A.; Campistol, J.; Feillet, F.; Giżewska, M.; Huijbregts, S. C.; Kearney, S.; Leuzzi, V.; Maillot, F.; Muntau, A. C.; van Rijn, M.; Trefz, F.; Walter, J. H.; van Spronsen, F. J. The Complete European Guidelines on Phenylketonuria: Diagnosis and Treatment. Orphanet Journal of Rare Diseases 2017, 12 (1), 1-56. https://doi.org/10.1186/s13023-017-0685-2.

(13) Colomé, C.; Artuch, R.; Lambruschini, N.; Cambra, F. J.; Campistol, J.; Vilaseca, M.-A. Is There a Relationship between Plasma Phenylalanine and Cholesterol in Phenylketonuric Patients under Dietary Treatment? Clinical Biochemistry 2001, 34 (5), 373-376. https://doi.org/10.1016/S0009-9120(01)00249-1.

(14) Schulpi, K. H.; Scarpalezou, A. Triglycerides, Cholesterol, HDL, LDL, and VLDL Cholesterol in Serum of Phenylketonuric Children under Dietary Control. Clinical Pediatrics 1989, 28 (10), 466-469. https://doi.org/10.1177/000992288902801007.

(15) Schulpis, K. H.; Karakonstantakis, T.; Bartzeliotou, A.; Karikas, G. A.; Papassotiriou, I. The Association of Serum Lipids, Lipoproteins and Apolipoproteins with Selected Trace Elements and Minerals in 
Phenylketonuric Patients on Diet. Clinical Nutrition 2004, 23 (3), 401-407. https://doi.org/10.1016/j.clnu.2003.09.006.

(16) Rocha, J. C.; van Spronsen, F. J.; Almeida, M. F.; Soares, G.; Quelhas, D.; Ramos, E.; Guimarães, J. T.; Borges, N. Dietary Treatment in Phenylketonuria Does Not Lead to Increased Risk of Obesity or Metabolic Syndrome. Molecular Genetics and Metabolism 2012, 107 (4), 659-663. https://doi.org/10.1016/j.ymgme.2012.10.006.

(17) LaVoie, S. M.; Harding, C. O.; Gillingham, M. B. Normal Fatty Acid Concentrations in Young Children with Phenylketonuria. Topics in Clinical Nutrition 2009, 24 (4), 333-340. https://doi.org/10.1097/TIN.0b013e3181c621fa.

(18) Galli, C.; Agostoni, C.; Mosconi, C.; Riva, E.; Carlo Salart, P.; Giovannini, M. Reduced Plasma C-20 and C-22 Polyunsaturated Fatty Acids in Children with Phenylketonuria during Dietary Intervention. The Journal of Pediatrics 1991, 119 (4), 562-567. https://doi.org/10.1016/S00223476(05)82405-9.

(19) Moseley, K.; Koch, R.; Moser, A. B. Lipid Status and Long-Chain Polyunsaturated Fatty Acid Concentrations in Adults and Adolescents with Phenylketonuria on Phenylalanine-Restricted Diet. Journal of Inherited Metabolic Disease 2002, 25 (1), 56-64. https://doi.org/10.1023/A:1015142001578.

(20) Aldámiz-Echevarría, L.; Lage, S.; Prieto, J. A.; Andrade, F. Polyunsaturated Fatty Acids and Growth in Healthy Children and Some Rare Diseases. In Handbook of Growth and Growth Monitoring in Health and Disease; Preedy, V. R., Ed.; Springer New York: New York, NY, 2012; pp 25972618.

(21) van Gool, C. J. A. W.; van Houwelingen, A. C.; Hornstra, G. The Essential Fatty Acid Status in Phenylketonuria Patients under Treatment. The Journal of Nutritional Biochemistry 2000, 11 (11-12), 543-547. https://doi.org/10.1016/S0955-2863(00)00111-X.

(22) Sanjurjo, P.; Perteagudo, L.; Soriano, J. R.; Vilaseca, A.; Campistol, J. Polyunsaturated Fatty Acid Status in Patients with Phenylketonuria. Journal of Inherited Metabolic Disease 1994, 17 (6), 704-709. https://doi.org/10.1007/BF00712012.

(23) Beblo, S.; Reinhardt, H.; Demmelmair, H.; Muntau, A. C.; Koletzko, B. Effect of Fish Oil Supplementation on Fatty Acid Status, Coordination, and Fine Motor Skills in Children with Phenylketonuria. The Journal of $\begin{array}{lllll}\text { Pediatrics } & 2007, & \text { (5), }\end{array}$ https://doi.org/10.1016/j.jpeds.2006.12.011. 
(24) Zárate, R.; el Jaber-Vazdekis, N.; Tejera, N.; Pérez, J. A.; Rodríguez, C. Significance of Long Chain Polyunsaturated Fatty Acids in Human Health. Clinical and Translational Medicine 2017, 6. https://doi.org/10.1186/s40169-017-0153-6.

(25) Calder, P.C.; Mechanisms of Action of (n-3) Fatty Acids, Journal of Nutrition 2012, 142 (3), 592S-599S. https://doi.org/10.3945/jn.111.155259.

(26) Koletzko, B.; Sauerwald, T.; Demmelmair, H.; Herzog, M.; Schenck, U. von; Böhles, H.; Wendel, U.; Seidel, J. Dietary Long-Chain Polyunsaturated Fatty Acid Supplementation in Infants with Phenylketonuria: A Randomized Controlled Trial. Journal of Inherited Metabolic Disease 2007, 30 (3), 326332. https://doi.org/10.1007/s10545-007-0491-4.

(27) Jans, J. J.; de Sain-van der Velden, M. G. M.; van Hasselt, P. M.; van den Hurk, D. T. A. M.; Vaz, F. M.; Visser, G.; Verhoeven-Duif, N. M. Supplementation with a Powdered Blend of PUFAs Normalizes DHA and AA Levels in Patients with PKU. Molecular Genetics and Metabolism 2013, 109 (2), 121-124. https://doi.org/10.1016/j.ymgme.2013.03.006.

(28) Agostoni, C.; Riva, E.; Biasucci, G.; Luotti, D.; Bruzzese, M. G.; Marangoni, F.; Giovannini, M. The Effects of N-3 and n-6 Polyunsaturated Fatty Acids on Plasma Lipids and Fatty Acids of Treated Phenylketonuric Children. Prostaglandins, Leukotrienes and Essential Fatty Acids 1995, 53 (6), 401404. https://doi.org/10.1016/0952-3278(95)90103-5.

(29) Demmelmair, H.; MacDonald, A.; Kotzaeridou, U.; Burgard, P.; GonzalezLamuno, D.; Verduci, E.; Ersoy, M.; Gokcay, G.; Alyanak, B.; Reischl, E.; Müller-Felber, W.; Faber, F. L.; Handel, U.; Paci, S.; Koletzko, B. Determinants of Plasma Docosahexaenoic Acid Levels and Their Relationship to Neurological and Cognitive Functions in PKU Patients: A Double Blind Randomized Supplementation Study. Nutrients 2018, 10 (12), 1944. https://doi.org/10.3390/nu10121944.

(30) Agostoni, C.; Harvie, A.; McCulloch, D. L.; Demellweek, C.; Cockburn, F.; Giovannini, M.; Murray, G.; Harkness, R. A.; Riva, E. A Randomized Trial of Long-Chain Polyunsaturated Fatty Acid Supplementation in Infants with Phenylketonuria. Developmental Medicine \& Child Neurology 2006, 48 (3), 207-212. https://doi.org/10.1017/S0012162206000442.

(31) Cleary, M. A.; Feillet, F.; White, F. J.; Vidailhet, M.; MacDonald, A.; Grimsley, A.; Maurin, N.; de Baulny, H. O.; Rutherford, P. J. Randomised Controlled Trial of Essential Fatty Acid Supplementation in Phenylketonuria. European Journal of Clinical Nutrition 2006, 60 (7), 915920. https://doi.org/10.1038/sj.ejcn.1602401.

(32) Risé, P.; Eligini, S.; Ghezzi, S.; Colli, S.; Galli, C. Fatty Acid Composition of Plasma, Blood Cells and Whole Blood: Relevance for the Assessment of 
the Fatty Acid Status in Humans. Prostaglandins, Leukotrienes and Essential Fatty Acids 2007, 76 (6), 363-369. https://doi.org/10.1016/j.plefa.2007.05.003.

(33) Giovannini, M.; Verduci, E.; Radaelli, G.; Lammardo, A.; Minghetti, D.; Cagnoli, G.; Salvatici, E.; Riva, E. Long-Chain Polyunsaturated Fatty Acids Profile in Plasma Phospholipids of Hyperphenylalaninemic Children on Unrestricted Diet. Prostaglandins, Leukotrienes and Essential Fatty Acids 2011, 84 (1-2), 39-42. https://doi.org/10.1016/j.plefa.2010.09.003.

(34) Ferreira, H. B.; Melo, T.; Monteiro, A.; Paiva, A.; Domingues, P.; Domingues, M. R. Serum Phospholipidomics Reveals Altered Lipid Profile and Promising Biomarkers in Multiple Sclerosis. Archives of Biochemistry and Biophysics 2021, 697, 108672. https://doi.org/10.1016/j.abb.2020.108672.

(35) Anjo, S.; Feiteira, E.; Cerveira, F.; Melo, T.; Reboredo, A.; Colombo, S.; Dantas, R.; Costa, E.; Moreira, A. S. P.; Santos, S.; Campos, A.; Ferreira, R.; Domingues, P.; Domingues, M.R.M. Lipidomics reveals similar changes in serum phospholipid signatures of overweight and obese pediatric subjects, Journal of Proteome Research 2018, 18 (8), 3174-3183. https://doi.org/10.1021/acs.jproteome.9b00249.

(36) Bartlett, E. M.; Lewis, D. H. Spectrophotometric Determination of Phosphate Esters in the Presence and Absence of Orthophosphate. Analytical Biochemistry 1970, 36 (1), 159-167. https://doi.org/10.1016/0003-2697(70)90343-X.

(37) Sousa, B.; Melo, T.; Campos, A.; Moreira, A. S. P.; Maciel, E.; Domingues, P.; Carvalho, R. P.; Rodrigues, T. R.; Girão, H.; Domingues, M. R. M. Alteration in Phospholipidome Profile of Myoblast H9c2 Cell Line in a Model of Myocardium Starvation and Ischemia. Journal of Cellular Physiology 2016, 231 (10), 2266-2274. https://doi.org/10.1002/jcp.25344.

(38) Chapman, G. W. A Conversion Factor to Determine Phospholipid Content in Soybean and Sunflower Crude Oils. Journal of the American Oil Chemists Society 1980, $57 \quad$ (9), 299-302. https://doi.org/10.1007/BF02662211.

(39) Aued-Pimentel, S.; Lago, J. H. G.; Chaves, M. H.; Kumagai, E. E. Evaluation of a Methylation Procedure to Determine Cyclopropenoids Fatty Acids from Sterculia Striata St. Hil. Et Nauds Seed Oil. Journal of Chromatography A 2004, 1054 (1), 235-239. https://doi.org/10.1016/j.chroma.2004.07.090. https://www.lipidmaps.org/resources/lipidweb/index.php?page=ms/methes ters/me-arch/index.htm (accessed Sep 23, 2020). 
(41) Pluskal, T.; Castillo, S.; Villar-Briones, A.; Orešič, M. MZmine 2: Modular Framework for Processing, Visualizing, and Analyzing Mass SpectrometryBased Molecular Profile Data. BMC Bioinformatics 2010, 11 (1), 395. https://doi.org/10.1186/1471-2105-11-395.

(42) R: The R Project for Statistical Computing https://www.r-project.org/ (accessed Sep 14, 2020).

(43) RStudio | Open source \& professional software for data science teams https://rstudio.com/ (accessed Sep 14, 2020).

(44) Xia, J.; Wishart, D. S. Using MetaboAnalyst 3.0 for Comprehensive Metabolomics Data Analysis. Current Protocols in Bioinformatics 2016, 55, 14.10.1-14.10.91. https://doi.org/10.1002/cpbi.11.

(45) Karpievitch, Y. V.; Nikolic, S. B.; Wilson, R.; Sharman, J. E.; Edwards, L. M. Metabolomics Data Normalization with EigenMS. PLOS ONE 2014, 9 (12), e116221. https://doi.org/10.1371/journal.pone.0116221.

(46) Stacklies, W.; Redestig, H.; Scholz, M.; Walther, D.; Selbig, J. PcaMethods-a Bioconductor Package Providing PCA Methods for Incomplete Data. Bioinformatics 2007, 23 (9), 1164-1167. https://doi.org/10.1093/bioinformatics/btm069.

(47) Benjamini, Y.; Hochberg, Y. Controlling the False Discovery Rate: A Practical and Powerful Approach to Multiple Testing. Journal of the Royal Statistical Society. Series B (Methodological) 1995, 57 (1), 289-300.

(48) pheatmap: pretty heatmaps version 1.0.12 from CRAN https://rdrr.io/cran/pheatmap/ (accessed Sep 11, 2020).

(49) Create Elegant Data Visualisations Using the Grammar of Graphics https://ggplot2.tidyverse.org/ (accessed Sep 14, 2020).

(50) Wickham, H. The Split-Apply-Combine Strategy for Data Analysis. Journal of Statistical Software 2011, 40 (1), 1-29. https://doi.org/10.18637/jss.v040.i01.

(51) dplyr: A Grammar of Data Manipulation version 1.0.2 from CRAN https://rdrr.io/cran/dplyr/ (accessed Sep 14, 2020).

(52) tidyr: Tidy Messy Data version 1.1.2 from CRAN https://rdrr.io/cran/tidyr/ (accessed Sep 14, 2020).

(53) ggrepel: Automatically Position Non-Overlapping Text Labels with "ggplot2" version 0.8.2 from CRAN https://rdrr.io/cran/ggrepel/ (accessed Sep 14, 2020). 
(54) Azabdaftari, A.; van der Giet, M.; Schuchardt, M.; Hennermann, J. B.; Plöckinger, U.; Querfeld, U. The Cardiovascular Phenotype of Adult Patients with Phenylketonuria. Orphanet Journal of Rare Diseases 2019, 14 (1), 213. https://doi.org/10.1186/s13023-019-1188-0.

(55) Stroup, B. M.; Nair, N.; Murali, S. G.; Broniowska, K.; Rohr, F.; Levy, H. L.; Ney, D. M. Metabolomic Markers of Essential Fatty Acids, Carnitine, and Cholesterol Metabolism in Adults and Adolescents with Phenylketonuria. The Journal of Nutrition 2018, 148 (2), 194-201. https://doi.org/10.1093/jn/nxx039.

(56) Quehenberger, O.; Armando, A. M.; Brown, A. H.; Milne, S. B.; Myers, D. S.; Merrill, A. H.; Bandyopadhyay, S.; Jones, K. N.; Kelly, S.; Shaner, R. L.; Sullards, C. M.; Wang, E.; Murphy, R. C.; Barkley, R. M.; Leiker, T. J.; Raetz, C. R. H.; Guan, Z.; Laird, G. M.; Six, D. A.; Russell, D. W.; McDonald, J. G.; Subramaniam, S.; Fahy, E.; Dennis, E. A. Lipidomics Reveals a Remarkable Diversity of Lipids in Human Plasma,. Journal of Lipid Research 2010, 51 (11), 3299-3305. https://doi.org/10.1194/jlr.M009449.

(57) Glaser, C.; Demmelmair, H.; Koletzko, B. High-Throughput Analysis of Fatty Acid Composition of Plasma Glycerophospholipids. J. Lipid Res. 2010, 51 (1), 216-221. https://doi.org/10.1194/jlr.D000547.

(58) Yi, S. H. L.; Kable, J. A.; Evatt, M. L.; Singh, R. H. A Randomized, PlaceboControlled, Double-Blind Trial of Supplemental Docosahexaenoic Acid on Cognitive Processing Speed and Executive Function in Females of Reproductive Age with Phenylketonuria: A Pilot Study. Prostaglandins, Leukotrienes and Essential Fatty Acids 2011, 85 (6), 317-327. https://doi.org/10.1016/j.plefa.2011.09.004.

(59) Davis, B. C.; Kris-Etherton, P. M. Achieving Optimal Essential Fatty Acid Status in Vegetarians: Current Knowledge and Practical Implications. AmThe American Journal of Clinical Nutrition J Clin Nutr 2003, 78 (3), 640S-646S. https://doi.org/10.1093/ajcn/78.3.640S.

(60) Koletzko, B.; Beblo, S.; Demmelmair, H.; Müller-Felber, W.; Hanebutt, F. L. Does Dietary DHA Improve Neural Function in Children? Observations in Phenylketonuria. Prostaglandins, Leukotrienes, and Essential Fatty Acids 2009, 81 (2-3), 159-164. https://doi.org/10.1016/j.plefa.2009.06.006.

(61) Arterburn, L. M.; Hall, E. B.; Oken, H. Distribution, Interconversion, and Dose Response of N-3 Fatty Acids in Humans. The American Journal of Clinical Nutrition 2006, 83 (6), 1467S-1476S. https://doi.org/10.1093/ajcn/83.6.1467S. 
(62) Lee, J.-H. Polyunsaturated Fatty Acids in Children. Pediatric Gastroenterology, Hepatology \& Nutrition 2013, 16 (3), 153-161. https://doi.org/10.5223/pghn.2013.16.3.153.

(63) Calder, P. C. Eicosapentaenoic and Docosahexaenoic Acid Derived Specialised Pro-Resolving Mediators: Concentrations in Humans and the Effects of Age, Sex, Disease and Increased Omega-3 Fatty Acid Intake. Biochimie 2020, 178, 105-123. https://doi.org/10.1016/j.biochi.2020.08.015.

(64) Calder, P. C.; Yaqoob, P. Omega-3 Polyunsaturated Fatty Acids and Human Health Outcomes. BioFactors 2009, 35 (3), 266-272. https://doi.org/10.1002/biof.42.

(65) Deon, M.; Sitta, A.; Faverzani, J. L.; Guerreiro, G. B.; Donida, B.; Marchetti, D. P.; Mescka, C. P.; Ribas, G. S.; Coitinho, A. S.; Wajner, M.; Vargas, C. R. Urinary Biomarkers of Oxidative Stress and Plasmatic Inflammatory Profile in Phenylketonuric Treated Patients. International Journal of Developmental Neuroscience 2015, 47, 259-265. https://doi.org/10.1016/j.ijdevneu.2015.10.001.

(66) Sakamoto, A.; Saotome, M.; Iguchi, K.; Maekawa, Y. Marine-Derived Omega-3 Polyunsaturated Fatty Acids and Heart Failure: Current Understanding for Basic to Clinical Relevance. International Journal of Molecular Sciences 2019, 20 (16). https://doi.org/10.3390/jms20164025.

(67) Méndez, L.; Dasilva, G.; Taltavull, N.; Romeu, M.; Medina, I. Marine Lipids on Cardiovascular Diseases and Other Chronic Diseases Induced by Diet: An Insight Provided by Proteomics and Lipidomics. Marine Drugs 2017, 15 (8). https://doi.org/10.3390/md15080258.

(68) Pacetti, D.; Lucci, P.; Boselli, E.; Frega, N. G. Effect of Antioxidant-Enriched Foods on Plasma: Phospholipid Molecular Species Composition. European Journal of Lipid Science and Technology 2009, 111 (12), 1201-1211. https://doi.org/10.1002/ejlt.200900013.

(69) Agostoni, C.; Massetto, N.; Biasucci, G.; Rottoli, A.; Bonvissuto, M.; Bruzzese, M.; Giovannini, M.; Riva, E. Effects of Long-Chain Polyunsaturated Fatty Acid Supplementation on Fatty Acid Status and Visual Function in Treated Children with Hyperphenylalaninemia. The Journal of Pediatrics 2000, 137 (4), 504-509. https://doi.org/10.1067/mpd.2000.108398.

(70) Braverman, N. E.; Moser, A. B. Functions of Plasmalogen Lipids in Health and Disease. Biochimica et Biophysica Acta (BBA) - Molecular Basis of Disease 2012, $1822 \quad$ (9), $1442-1452$. https://doi.org/10.1016/j.bbadis.2012.05.008. 
(71) Lessig, J.; Fuchs, B. Plasmalogens in Biological Systems: Their Role in Oxidative Processes in Biological Membranes, Their Contribution to Pathological Processes and Aging and Plasmalogen Analysis. Current Medicinal Chemistry 2009, 16 (16), 2021-2041. https://doi.org/10.2174/092986709788682164.

(72) Leßig, J.; Schiller, J.; Arnhold, J.; Fuchs, B. Hypochlorous Acid-Mediated Generation of Glycerophosphocholine from Unsaturated Plasmalogen Glycerophosphocholine Lipids. Journal of Lipid Research 2007, 48 (6), 1316-1324. https://doi.org/10.1194/jr.M600478-JLR200.

(73) Stamler, C. J.; Breznan, D.; Neville, T. A.; Viau, F. J.; Camlioglu, E.; Sparks, D. L. Phosphatidylinositol Promotes Cholesterol Transport in Vivo. Journal of Lipid Research 2000, 41 (8), 1214-1221.

(74) Sasaki, T.; Sasaki, J.; Sakai, T.; Takasuga, S.; Suzuki, A. The Physiology of Phosphoinositides. Biological \& Pharmaceutical Bulletin 2007, 30 (9), 1599-1604. https://doi.org/10.1248/bpb.30.1599.

(75) Barthel, A.; Klotz, L.-O. Phosphoinositide 3-Kinase Signaling in the Cellular Response to Oxidative Stress. Biol Chem 2005, 386 (3), 207-216. https://doi.org/10.1515/BC.2005.026.

(76) Leventis, P. A.; Grinstein, S. The Distribution and Function of Phosphatidylserine in Cellular Membranes. Annual Review of Biophysics 2010, 39 (1), 407-427. https://doi.org/10.1146/annurev.biophys.093008.131234.

(77) Otsuka, M.; Tsuchiya, S.; Aramaki, Y. Involvement of ERK, a MAP Kinase, in the Production of TGF- $\beta$ by Macrophages Treated with Liposomes Composed of Phosphatidylserine. Biochemical and Biophysical Research Communications 2004, 324 (4), 1400-1405. https://doi.org/10.1016/j.bbrc.2004.09.198.

(78) Iqbal, J.; Walsh, M. T.; Hammad, S. M.; Hussain, M. M. Sphingolipids and Lipoproteins in Health and Metabolic Disorders. Trends in Endocrinology \& Metabolism 2017, 28 (7), 506-518. https://doi.org/10.1016/j.tem.2017.03.005.

(79) Pena, M. J.; Rocha, J. C.; Borges, N. Amino Acids, Glucose Metabolism and Clinical Relevance for Phenylketonuria Management. 2015.

(80) Laplante, M.; Sabatini, D. M. An Emerging Role of MTOR in Lipid Biosynthesis. Current Biology 2009, 19 (22), R1046-R1052. https://doi.org/10.1016/j.cub.2009.09.058. 
Table of Contents (TOC) graphic

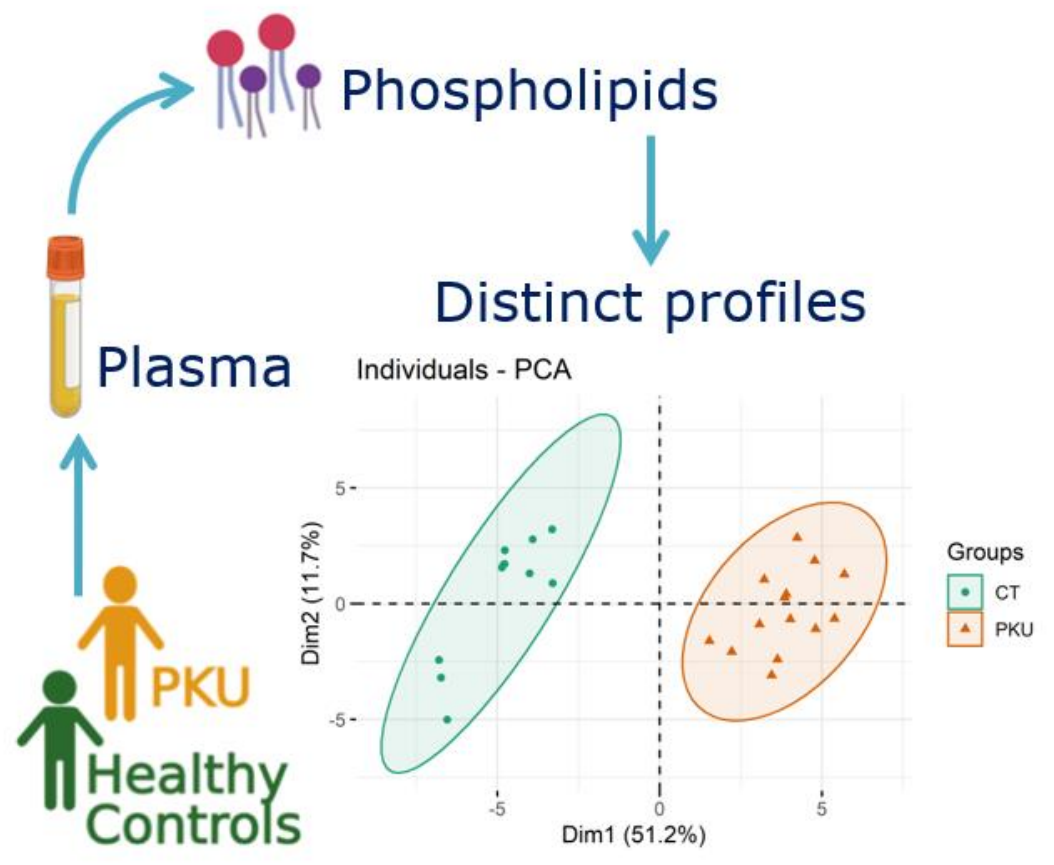




\section{Supplementary Information}

\section{Plasma phospholipidomic profile differs between children with phenylketonuria and healthy children}

Inês M. S. Guerraa, Luísa Diogob, Marisa Pinhoc, Tânia Meloa,d, Pedro Domingues ${ }^{a}$, M. Rosário Domingues ${ }^{\mathrm{a}, \mathrm{d}}$, Ana S. P.Moreira $\mathrm{a}^{\mathrm{a}, \mathrm{e},{ }^{\star}}$

a Mass Spectrometry Center, LAQV-REQUIMTE, Department of Chemistry, University of Aveiro, Campus Universitário de Santiago, 3810-193 Aveiro, Portugal

${ }^{b}$ Reference Center of Inherited Metabolic Diseases, Hospital Pediátrico, Centro Hospitalar e Universitário de Coimbra, 3000-075 Coimbra, Portugal

' ECOMARE, CESAM - Center for Environmental and Marine Studies, Department of Biology, University of Aveiro, Campus de Santiago, 3810-193 Aveiro, Portugal

${ }^{d}$ CESAM - Centre for Environmental and Marine Studies, Department of Chemistry, University of Aveiro, Campus Universitário de Santiago, 3810-193 Aveiro, Portugal

e CICECO - Aveiro Institute of Materials, Department of Chemistry, University of Aveiro, Campus Universitário de Santiago, 3810-193 Aveiro, Portugal

*Corresponding author. E-mail address: ana.moreira@ua.pt

\section{Table of contents:}

Supplementary Table S1. Data collected for each of PKU patients.

Supplementary Table S2. Significant variations between the FA identified by GC-MS from PKU and CT groups.

Supplementary Table S3. Phospholipids and sphingolipids identified by HILIC-MS and MS/MS of phospholipid $(\mathrm{PL})$-enriched extracts obtained from plasma samples collected, in fasting, from PKU patients and healthy controls (mass error $<5 \mathrm{ppm}$ ).

Supplementary Table S4. The 146 lipid species showing significant variation between PKU and control (CT) groups. Figure S1. Representative MS/MS spectra of phosphatidylcholine (PC) lipid species.

Supplementary Figure S2. Representative MS/MS spectra of sphingomyelin (SM) lipid species.

Supplementary Figure S3. Representative MS/MS spectrum of ceramide (Cer) lipid species.

Supplementary Figure S4. Representative MS/MS spectra of phosphatidylethanolamine (PE) lipid species.

Supplementary Figure S5. Representative MS/MS spectrum of phosphatidylglycerol (PG) lipid species.

Supplementary Figure S6. Representative MS/MS spectrum of phosphatidylglycerol (PI) lipid species.

Supplementary Figure S7. Representative MS/MS spectra of isomeric plasmanyl (O-) and plasmenyl (P-) phosphatidylcholine (PC) lipid species, eluting at the same retention time in LC-MS. Supplementary Figure S8. Representative MS/MS spectra of oxidized phosphatidylcholine (PC) lipid species. 
Supplementary Table S1. Data collected for each of phenylketonuric (PKU) patients.

\begin{tabular}{|c|c|c|c|c|c|c|c|}
\hline Age & Sex & $\begin{array}{l}\text { Forms of } \\
\text { the disease }\end{array}$ & $\begin{array}{c}\text { Phe (mg/dl) } \\
\text { screening }\end{array}$ & $\begin{array}{l}\text { AA mixture } \\
\text { supplement }\end{array}$ & $\begin{array}{c}\text { PUFA } \\
\text { supplement }\end{array}$ & \multicolumn{2}{|c|}{$P A H$ gene } \\
\hline 17 & $\mathrm{M}$ & Moderate & 13.9 & Yes & No & p.R261Q & p.L308F \\
\hline 14 & $\mathrm{~F}$ & Mild & 9.1 & Yes & Keyomega $\AA$ & p.165T & p.R261Q \\
\hline 14 & $\mathrm{~F}$ & Moderate & 15 & Yes & Keyomega $\AA$ & p.R243X & p.R243X \\
\hline 13 & M & Mild & 6.8 & Yes & No & p.R176L & p.R243Q \\
\hline 12 & $\mathrm{~F}$ & Moderate & 16.5 & Yes & Keyomega® & p.R252W & p.R270K \\
\hline 12 & M & Classic & 20 & Yes & DHA richoil® & p.R158Q & p.R158Q \\
\hline 12 & $\mathrm{~F}$ & Moderate & 11 & Yes & DHA richoilß & p.R158Q & p.L249F \\
\hline 11 & $\mathrm{~F}$ & Moderate & 14.7 & Yes & DHA richoil $\circledast$ & p.R261Q & p.R270K \\
\hline 8 & $\mathrm{~F}$ & Mild ${ }^{*}$ & 6.5 & No & No & p.G352Vfsx 12 & p.1421T \\
\hline 7 & M & Classic & 27.2 & Yes & No & IVS10-11G>A & IVS12+1G>A \\
\hline 6 & $\mathrm{~F}$ & Moderate & 13.8 & Yes & No & p.165T & p.P281L \\
\hline 4 & M & Mild\# & 7.9 & Yes & No & p.R261Q & p.R261Q \\
\hline 3 & M & Moderate ${ }^{\#}$ & 15.6 & Yes & No & na & na \\
\hline 3 & M & Mild" & 8 & Yes & No & p.R270K & p.A403V \\
\hline 4 & M & Classic" & 26.3 & Yes & No & p.R270K & IVS10-11G>A \\
\hline
\end{tabular}


Supplementary Table S2. Significant variations between the FA identified by GC-MS from PKU and CT groups, sorted by increasing number of carbon atoms and double bonds. FA are labelled as follows: $F A x x: i$ ( $x x=$ number of carbon atoms; $i=$ number of double bonds), followed by $n$-y for unsaturated FA ( $\mathrm{y}=\mathrm{double}$-bond position related to the methyl end). Significant differences $(q$-values $<0.05)$ between the groups revealed by Welch t-test or Mann-Whitney test are marked with * if $q<0.05$ and ${ }^{* *}$ if $q<0.01$. ns - not significant.

\begin{tabular}{ccc}
\hline Fatty acids & FDR, $q$-value & $\begin{array}{c}\text { Statistical } \\
\text { significance } \\
\text { level }\end{array}$ \\
\hline $14: 0$ & 0.03179 & $*$ \\
\hline $16: 0$ & 0.065880 & ns \\
\hline $18: 0$ & 0.027164 & $*$ \\
\hline $18: 1 n-9$ & 0.005159 & $* *$ \\
\hline $18: 1$ & 0.003238 & $* \star$ \\
\hline $18: 2 n-6$ & 0.090307 & ns \\
\hline $20: 4 n-6$ & 0.152209 & $n s$ \\
\hline $20: 5 n-3$ & 0.033109 & $*$ \\
\hline $22: 6 n-3$ & 0.027164 & $*$ \\
\hline
\end{tabular}


Supplementary Table S3. Phospholipids and sphingolipids identified by HILIC-MS and MS/MS of phospholipid $(\mathrm{PL})$-enriched extracts obtained from plasma samples collected, in fasting, from PKU patients and healthy controls (mass error $<5 \mathrm{ppm}$ ). Observed $m / z$ values and respective errors were checked for all samples. Lipid species are labelled as follows: $A A A A(x x: i)$ ( $A A A A=$ lipid class abbreviation; $x x=$ number of carbon atoms in fatty acid(s); i=number of double bonds). The 'O-' prefix is used for plasmanyl species to indicate the presence of an alkyl ether substituent, whereas the 'P-' prefix is used for plasmenyl species to indicate the alk-1-enyl ether substituent. Molecular species with known fatty acyl constituents are labelled using (sn-1/sn-2) nomenclature, considering that in animals the sn-1 position generally contains smaller and saturated fatty acids, while fatty acids with a higher unsaturation degree are located at $s n-2$. *, Lipid species identified only by retention time and mass accuracy. ${ }^{* *}$, Lipid species identified by retention time, mass accuracy and confirmation of polar head group by MS/MS of $[\mathrm{M}+\mathrm{H}]^{+}$ions. Lipid class abbreviations: Cer, ceramide; PC, phosphatidylcholine; LPC, lysophosphatidylcholine; SM, sphingomyelin; PE, phosphatidylethanolamine; LPE, lysophosphatidylethanolamine; PG, phosphatidylglycerol; LPG, lysophosphatidylglycerol; PI, phosphatidylinositol; PS, phosphatidylserine.

\begin{tabular}{|c|c|c|c|c|c|}
\hline Lipid species & $\begin{array}{l}\text { Theoretical } \\
m / z\end{array}$ & $\begin{array}{l}\text { Observed } \\
m / z\end{array}$ & $\begin{array}{l}\text { Error } \\
\text { (ppm) }\end{array}$ & Fatty acyl chain(s) & Formula \\
\hline $\operatorname{Cer}(d 30: 1)$ & 482.4573 & 482.4563 & -2.1121 & $(\mathrm{~d} 18: 1 / 12: 0)$ & $\mathrm{C} 30 \mathrm{H} 60 \mathrm{NO} 3$ \\
\hline $\operatorname{Cer}(\mathrm{d} 34: 1)$ & 538.5199 & 538.5186 & -2.4493 & * & $\mathrm{C} 34 \mathrm{H} 68 \mathrm{NO} 3$ \\
\hline HexCer(d38:0) & 758.6510 & 758.6522 & 1.5897 & * & C44H88NO8 \\
\hline \multicolumn{6}{|c|}{$\begin{array}{c}\text { PC identified as }[\mathrm{M}+\mathrm{H}]^{+} \\
\left.\text {(determination of fatty acyl chains by } \mathrm{MS} / \mathrm{MS} \text { of }\left[\mathrm{M}+\mathrm{CH}_{3} \mathrm{COO}\right]^{-}\right)\end{array}$} \\
\hline $\mathrm{PC}(0-28: 0)$ & 664.5281 & 664.5280 & -0.1761 & ** & C36H75NO7P \\
\hline $\mathrm{PC}(\mathrm{O}-30: 1) / \mathrm{PC}(\mathrm{P}-30: 0)$ & 690.5438 & 690.5426 & -1.6900 & ** & C38H77NO7P \\
\hline $\mathrm{PC}(\mathrm{O}-30: 0)$ & 692.5594 & 692.5584 & -1.4670 & ** & C38H79NO7P \\
\hline $\mathrm{PC}(30: 1)$ & 704.5230 & 704.5250 & 2.7934 & $(14: 0 / 16: 1)$ & C38H75NO8P \\
\hline $\mathrm{PC}(30: 0)$ & 706.5387 & 706.5404 & 2.4316 & $(14: 0 / 16: 0)$ & $\mathrm{C} 38 \mathrm{H} 77 \mathrm{NO} 8 \mathrm{P}$ \\
\hline $\mathrm{PC}(0-32: 0)$ & 720.5907 & 720.591 & 0.3927 & $(0-16: 0 / 16: 0)$ & C40H83NO7P \\
\hline$P C(32: 2)$ & 730.5387 & 730.5403 & 2.2148 & $(16: 1 / 16: 1)$ and $(14: 0 / 18: 2)$ & $\mathrm{C} 40 \mathrm{H} 77 \mathrm{NO} 8 \mathrm{P}$ \\
\hline$P C(32: 1)$ & 732.5543 & 732.5527 & -2.2265 & $(16: 0 / 16: 1)$ and $(14: 0 / 18: 1)$ & $\mathrm{C} 40 \mathrm{H} 79 \mathrm{NO} 8 \mathrm{P}$ \\
\hline$P C(32: 0)$ & 734.5700 & 734.5701 & 0.1606 & $(16: 0 / 16: 0)$ & $\mathrm{C} 40 \mathrm{H} 81 \mathrm{NO} 8 \mathrm{P}$ \\
\hline $\mathrm{PC}(\mathrm{O}-32: 0)+\mathrm{O}$ & 736.5856 & 736.5843 & -1.8083 & ** & $\mathrm{C} 40 \mathrm{H} 83 \mathrm{NO} 8 \mathrm{P}$ \\
\hline $\mathrm{PC}(\mathrm{O}-34: 4) / \mathrm{PC}(\mathrm{P}-34: 3)$ & 740.5599 & 740.5572 & -3.7021 & ** & $\mathrm{C} 42 \mathrm{H} 79 \mathrm{NO} 7 \mathrm{P}$ \\
\hline $\mathrm{PC}(\mathrm{O}-34: 3) / \mathrm{PC}(\mathrm{P}-34: 2)$ & 742.5751 & 742.5763 & 1.6604 & (O-16:1/18:2) and/or (P-16:0/18:2) & $\mathrm{C} 42 \mathrm{H} 81 \mathrm{NO} 7 \mathrm{P}$ \\
\hline $\mathrm{PC}(\mathrm{O}-34: 2) / \mathrm{PC}(\mathrm{P}-34: 1)$ & 744.5907 & 744.5914 & 0.9173 & (O-16:0/18:2) and (P-18:1/16:0) & $\mathrm{C} 42 \mathrm{H} 83 \mathrm{NO} 7 \mathrm{P}$ \\
\hline $\mathrm{PC}(\mathrm{O}-34: 1) / \mathrm{PC}(\mathrm{P}-34: 0)$ & 746.6064 & 746.6059 & -0.6255 & $\begin{array}{l}\mathrm{P}-18: 0 / 16: 0),(\mathrm{O}-16: 0 / 18: 1) \text { and } \\
\text { possible }(0-18: 1 / 16: 0)\end{array}$ & $\mathrm{C} 42 \mathrm{H} 85 \mathrm{NO} 7 \mathrm{P}$ \\
\hline $\mathrm{PC}(34: 1)$ & 760.5856 & 760.5847 & -1.2254 & $(16: 0 / 18: 1)$ & $\mathrm{C} 42 \mathrm{H} 83 \mathrm{NO} 8 \mathrm{P}$ \\
\hline$P C(P-36: 5)$ & 764.5594 & 764.5579 & -1.9841 & $(P-16: 0 / 20: 5)$ & C44H79NO7P \\
\hline $\mathrm{PC}(\mathrm{O}-36: 5) / \mathrm{PC}(\mathrm{P}-36: 4)$ & 766.5751 & 766.5757 & 0.8258 & $(\mathrm{O}-16: 1 / 20: 4)$ and/or $(\mathrm{P}-16: 0 / 20: 4)$ & C44H81NO7P \\
\hline $\mathrm{PC}(\mathrm{O}-36: 4) / \mathrm{PC}(\mathrm{P}-36: 3)$ & 768.5907 & 768.5912 & 0.6284 & $(\mathrm{P}-18: 1 / 18: 2)$ and $(\mathrm{O}-16: 0 / 20: 4)$ & C44H83NO7P \\
\hline $\mathrm{PC}(\mathrm{O}-36: 3) / \mathrm{PC}(\mathrm{P}-36: 2)$ & 770.6064 & 770.6035 & -3.7204 & $(\mathrm{O}-18: 1 / 18: 2)$ and/or (P-18:0/18:2) & C44H85NO7P \\
\hline $\mathrm{PC}(\mathrm{O}-36: 2) / \mathrm{PC}(\mathrm{P}-36: 1)$ & 772.6220 & 772.6194 & -3.3859 & $\begin{array}{l}(\mathrm{O}-18: 0 / 18: 2),(\mathrm{P}-18: 1 / 18: 0) \text { and } \\
(\mathrm{O}-18: 1 / 18: 1) \text { and/or }(\mathrm{P}-18: 0 / 18: 1)\end{array}$ & $\mathrm{C} 44 \mathrm{H} 87 \mathrm{NO} 7 \mathrm{P}$ \\
\hline
\end{tabular}




\begin{tabular}{|c|c|c|c|c|c|}
\hline $\mathrm{PC}(34: 2)+\mathrm{O}$ & 774.5649 & 774.5661 & 1.5531 & $(16: 0 / 18: 2+0)$ & C42H81NO9P \\
\hline $\mathrm{PC}(34: 1)+\mathrm{O}$ & 776.5805 & 776.5773 & -3.7948 & ** & C42H83NO9P \\
\hline $\mathrm{PC}(36: 6)$ & 778.5387 & 778.5379 & -1.0044 & $(14: 0 / 22: 6)$ & $\mathrm{C} 44 \mathrm{H} 77 \mathrm{NO} 8 \mathrm{P}$ \\
\hline $\mathrm{PC}(36: 5)$ & 780.5543 & 780.5535 & -1.0646 & $\begin{array}{l}(16: 0 / 20: 5),(16: 1 / 20: 4) \text { and } \\
(18: 2 / 18: 3)\end{array}$ & C44H79NO8P \\
\hline $\operatorname{PC}(36: 4)$ & 782.5700 & 782.5707 & 0.9175 & $(16: 0 / 20: 4)$ and (18:2/18:2) & C44H81NO8P \\
\hline $\mathrm{PC}(36: 3)$ & 784.5856 & 784.5857 & 0.0867 & $(16: 0 / 20: 3)$ and (18:1/18:2) & C44H83NO8P \\
\hline $\mathrm{PC}(36: 2)$ & 786.6013 & 786.5999 & -1.7569 & $(18: 0 / 18: 2)$ and (18:1/18:1) & C44H85NO8P \\
\hline $\mathrm{PC}(\mathrm{P}-38: 6)$ & 790.5751 & 790.5715 & -2.6146 & $(\mathrm{P}-16: 0 / 22: 6)$ & C46H81NO7P \\
\hline PC(O-38:6)/PC(P-38:5) & 792.5907 & 792.5889 & -2.2925 & $(\mathrm{P}-18: 1 / 20: 4)$ and $(\mathrm{O}-16: 0 / 22: 6)$ & C46H83NO7P \\
\hline $\mathrm{PC}(\mathrm{O}-38: 5) / \mathrm{PC}(\mathrm{P}-38: 4)$ & 794.6064 & 794.6041 & -2.8530 & $(\mathrm{O}-18: 1 / 20: 4)$ and/or (P-18:0/20:4) & C46H85NO7P \\
\hline $\mathrm{PC}(\mathrm{O}-38: 4) / \mathrm{PC}(\mathrm{P}-38: 3)$ & 796.6220 & 796.6184 & -3.7860 & $* *$ & C46H87NO7P \\
\hline PC(O-38:3)/PC(P-38:2) & 798.6377 & 798.6342 & -1.5865 & ** & C46H89NO7P \\
\hline $\mathrm{PC}(38: 8)$ & 802.5387 & 802.5380 & -0.8498 & ** & $\mathrm{C} 46 \mathrm{H} 77 \mathrm{NO} 8 \mathrm{P}$ \\
\hline $\mathrm{PC}(38: 7)$ & 804.5543 & 804.5510 & -2.4001 & $(16: 1 / 22: 6)$ & $\mathrm{C} 46 \mathrm{H} 79 \mathrm{NO} 8 \mathrm{P}$ \\
\hline $\mathrm{PC}(38: 6)$ & 806.5700 & 806.5707 & 0.8902 & $(16: 0 / 22: 6)$ & $\mathrm{C} 46 \mathrm{H} 81 \mathrm{NO} 8 \mathrm{P}$ \\
\hline $\mathrm{PC}(38: 5)$ & 808.5856 & 808.5854 & -0.2869 & $(18: 1 / 20: 4)$ & $\mathrm{C} 46 \mathrm{H} 83 \mathrm{NO} 8 \mathrm{P}$ \\
\hline $\mathrm{PC}(36: 6)+2 \mathrm{O}$ & 810.5285 & 810.5310 & 3.0696 & ** & $\mathrm{C} 44 \mathrm{H} 77 \mathrm{NO} 10 \mathrm{P}$ \\
\hline $\mathrm{PC}(38: 4)$ & 810.6013 & 810.6022 & 1.1325 & $(18: 0 / 20: 4)$ & $\mathrm{C} 46 \mathrm{H} 85 \mathrm{NO} 8 \mathrm{P}$ \\
\hline $\mathrm{PC}(38: 3)$ & 812.6169 & 812.6161 & -1.0239 & $(18: 0 / 20: 3)$ and $(18: 2 / 20: 1)$ & C46H87NO8P \\
\hline $\mathrm{PC}(36: 4)+2 \mathrm{O}$ & 814.5598 & 814.5603 & 0.5991 & $(18: 2 / 18: 2+2 O)$ and $(16: 0 / 20: 4+2 O)$ & $\mathrm{C} 44 \mathrm{H} 81 \mathrm{NO} 10 \mathrm{P}$ \\
\hline $\mathrm{PC}(38: 2)$ & 814.6326 & 814.6301 & -3.0468 & ** & $\mathrm{C} 46 \mathrm{H} 89 \mathrm{NO} 8 \mathrm{P}$ \\
\hline $\operatorname{PC}(38: 1)$ & 816.6482 & 816.6462 & -2.4882 & ** & $\mathrm{C} 46 \mathrm{H} 91 \mathrm{NO} 8 \mathrm{P}$ \\
\hline $\mathrm{PC}(\mathrm{P}-40: 6)$ & 818.6064 & 818.6042 & -2.6472 & (P-18:0/22:6) & C48H85NO7P \\
\hline $\mathrm{PC}(\mathrm{O}-40: 6) / \mathrm{PC}(\mathrm{P}-40: 5)$ & 820.6220 & 820.6194 & -3.1878 & ** & C48H87NO7P \\
\hline $\mathrm{PC}(\mathrm{O}-40: 5) / \mathrm{PC}(\mathrm{P}-40: 4)$ & 822.6377 & 822.6345 & -3.8498 & ** & C48H89NO7P \\
\hline $\mathrm{PC}(\mathrm{O}-40: 4) / \mathrm{PC}(\mathrm{P}-40: 3)$ & 824.6533 & 824.6518 & -1.8396 & $(0-20: 0 / 20: 4)$ & C48H91NO7P \\
\hline $\mathrm{PC}(40: 10)$ & 826.5387 & 826.5368 & -2.2770 & ** & $\mathrm{C} 48 \mathrm{H} 77 \mathrm{NO} 8 \mathrm{P}$ \\
\hline $\mathrm{PC}(40: 9)$ & 828.5543 & 828.5508 & -3.6582 & ** & C48H79NO8P \\
\hline $\mathrm{PC}(40: 8)$ & 830.5699 & 830.5682 & -2.0853 & $(20: 4 / 20: 4)$ & $\mathrm{C} 48 \mathrm{H} 81 \mathrm{NO} 8 \mathrm{P}$ \\
\hline $\mathrm{PC}(40: 7)$ & 832.5856 & 832.5849 & -0.8792 & $(18: 1 / 22: 6)$ & C48H83NO8P \\
\hline $\mathrm{PC}(40: 6)$ & 834.6013 & 834.5990 & -2.7342 & $(18: 0 / 22: 6)$ & $\mathrm{C} 48 \mathrm{H} 85 \mathrm{NO} 8 \mathrm{P}$ \\
\hline$P C(40: 5)$ & 836.6169 & 836.6146 & -2.7874 & $* *$ & C48H87NO8P \\
\hline $\mathrm{PC}(40: 4)$ & 838.6326 & 838.6338 & 1.4524 & (18:0/22:4) and (20:0/20:4) & C48H89NO8P \\
\hline $\mathrm{PC}(42: 11)$ & 852.5543 & 852.5503 & -1.5612 & ** & $\mathrm{C} 50 \mathrm{H} 79 \mathrm{NO} 8 \mathrm{P}$ \\
\hline $\mathrm{PC}(42: 10)$ & 854.5700 & 854.5672 & -3.2554 & ** & $\mathrm{C} 50 \mathrm{H} 81 \mathrm{NO} 8 \mathrm{P}$ \\
\hline $\mathrm{PC}(40: 4)+\mathrm{O}$ & 854.6275 & 854.6303 & 3.2798 & ** & C48H89NO9P \\
\hline $\mathrm{PC}(42: 9)$ & 856.5856 & 856.5832 & -2.8392 & $* *$ & C50H83NO8P \\
\hline $\mathrm{PC}(42: 8)$ & 858.6013 & 858.5978 & -1.6096 & $(20: 4 / 22: 4)$ and $(20: 2 / 22: 6)$ & C50H85NO8P \\
\hline $\mathrm{PC}(42: 7)$ & 860.6169 & 860.6138 & -3.6392 & $(20: 1 / 22: 6)$ & C50H87NO8P \\
\hline $\mathrm{PC}(42: 6)$ & 862.6326 & 862.6328 & 0.2527 & $(20: 0 / 22: 6)$ & C50H89NO8P \\
\hline$P C(42: 5)$ & 864.6482 & 864.6464 & -2.1188 & $* *$ & C50H91NO8P \\
\hline $\mathrm{PC}(42: 4)$ & 866.6639 & 866.6623 & -1.8254 & ** & C50H93NO8P \\
\hline $\mathrm{PC}(40: 5)+2 \mathrm{O}$ & 868.6068 & 868.6044 & -2.7193 & ** & $\mathrm{C} 48 \mathrm{H} 87 \mathrm{NO} 10 \mathrm{P}$ \\
\hline $\mathrm{PC}(44: 12)$ & 878.5700 & 878.5672 & -3.1665 & ** & C52H81NO8P \\
\hline $\mathrm{PC}(44: 11)$ & 880.5856 & 880.5821 & -1.5126 & ** & C52H83NO8P \\
\hline PC(44:10) & 882.6013 & 882.5981 & -3.6053 & ** & C52H85NO8P \\
\hline
\end{tabular}




\begin{tabular}{|c|c|c|c|c|c|}
\hline $\mathrm{PC}(44: 9)$ & 884.6169 & 884.6129 & -3.7666 & ** & C52H87NO8P \\
\hline $\mathrm{PC}(44: 8)$ & 886.6326 & 886.6327 & 0.1331 & ** & C52H89NO8P \\
\hline $\mathrm{PC}(44: 5)$ & 892.6795 & 892.6802 & 0.7483 & $* *$ & C52H95NO8P \\
\hline $\mathrm{PC}(44: 4)$ & 894.6952 & 894.6927 & -2.7730 & $* *$ & C52H97NO8P \\
\hline \multicolumn{6}{|c|}{$\begin{array}{l}\text { LPC identified as [M }+\mathrm{H}^{+} \\
\left.\mathrm{n} \text { of fatty acyl chain by } \mathrm{MS} / \mathrm{MS} \text { of }\left[\mathrm{M}+\mathrm{CH}_{3} \mathrm{COO}\right]-\right)\end{array}$} \\
\hline $\operatorname{LPC}(14: 0)$ & 468.3090 & 468.3082 & -1.7446 & $(14: 0)$ & $\mathrm{C} 22 \mathrm{H} 47 \mathrm{NO} 7 \mathrm{P}$ \\
\hline $\operatorname{LPC}(16: 0)$ & 496.3403 & 496.3414 & 2.1840 & $(16: 0)$ & C24H51NO7P \\
\hline $\operatorname{LPC}(16: 1)$ & 494.3247 & 494.3255 & 1.6851 & $(16: 1)$ & C24H49NO7P \\
\hline $\operatorname{LPC}(16: 1)+\mathrm{O}$ & 510.3196 & 510.3189 & -1.3345 & $(16: 1+O)$ & C24H49NO8P \\
\hline LPC(18:0) & 524.3716 & 524.3726 & 1.8746 & $(18: 0)$ & C26H55NO7P \\
\hline $\operatorname{LPC}(18: 1)$ & 522.3560 & 522.3573 & 2.5519 & $(18: 1)$ & C26H53NO7P \\
\hline LPC(18:1)+O & 538.3509 & 538.3488 & -3.8674 & ** & C26H53NO8P \\
\hline LPC(18:2) & 520.3403 & 520.3397 & -1.1838 & $(18: 2)$ & C26H51NO7P \\
\hline $\operatorname{LPC}(18: 2)+20$ & 552.3301 & 552.3318 & 2.9928 & $* *$ & C26H51NO9P \\
\hline LPC(18:2)+O & 536.3352 & 536.3367 & 2.7371 & $(18: 2+O)$ & C26H51NO8P \\
\hline LPC(18:3) & 518.3247 & 518.3223 & 3.9092 & $(18: 3)$ & C26H49NO7P \\
\hline $\operatorname{LPC}(18: 3)+\mathrm{O}$ & 534.3196 & 534.3174 & -2.5865 & $(18: 3+O)$ & C26H49NO8P \\
\hline LPC(20:0) & 552.4029 & 552.4037 & 1.4174 & $(20: 0)$ & C28H59NO7P \\
\hline $\operatorname{LPC}(20: 1)$ & 550.3873 & 550.3887 & 2.6036 & $(20: 1)$ & C28H57NO7P \\
\hline $\operatorname{LPC}(20: 2)$ & 548.3716 & 548.3692 & -2.7664 & $(20: 2)$ & C28H55NO7P \\
\hline $\operatorname{LPC}(20: 3)$ & 546.3560 & 546.3563 & 0.6095 & $(20: 3)$ & C28H53NO7P \\
\hline $\operatorname{LPC}(20: 4)$ & 544.3403 & 544.3411 & 1.4403 & $(20: 4)$ & C28H51NO7P \\
\hline $\operatorname{LPC}(20: 4)+O$ & 560.3352 & 560.3337 & -2.7341 & * & C28H51NO8P \\
\hline LPC(20:5) & 542.3247 & 542.3219 & -3.2582 & $(20: 5)$ & C28H49NO7P \\
\hline $\operatorname{LPC}(22: 0)$ & 580.4342 & 580.4328 & -2.4413 & ** & С30H63NO7P \\
\hline $\operatorname{LPC}(22: 1)$ & 578.4186 & 578.4179 & -1.1514 & ** & $\mathrm{C} 30 \mathrm{H} 61 \mathrm{NO} 7 \mathrm{P}$ \\
\hline LPC(22:4) & 572.3716 & 572.3714 & -0.3791 & $(22: 4)$ & $\mathrm{C} 30 \mathrm{H} 55 \mathrm{NO}$-P \\
\hline $\operatorname{LPC}(22: 5)$ & 570.3560 & 570.3561 & 0.2332 & ** & $\mathrm{C} 30 \mathrm{H} 53 \mathrm{NO}$-P \\
\hline $\operatorname{LPC}(22: 6)$ & 568.3403 & 568.3395 & -1.4358 & $(22: 6)$ & $\mathrm{C} 30 \mathrm{H} 51 \mathrm{NO} 7 \mathrm{P}$ \\
\hline $\operatorname{LPC}(24: 0)$ & 608.4655 & 608.4648 & -1.1784 & ** & C32H67NO7P \\
\hline LPC $(O-16: 0)$ & 482.3611 & 482.3602 & -1.7663 & $(0-16: 0)$ & C24H53NO6P \\
\hline LPC $(O-16: 1) / L P C(P-16: 0)$ & 480.3454 & 480.3461 & 1.4531 & $(P-16: 0)$ & $\mathrm{C} 24 \mathrm{H} 51 \mathrm{NO} 6 \mathrm{P}$ \\
\hline $\operatorname{LPC}(\mathrm{O}-18: 0)$ & 510.3924 & 510.3927 & 0.6818 & $(0-18: 0)$ & C26H57NO6P \\
\hline LPC(O-18:1)/LPC(P-18:0) & 508.3767 & 508.376 & -1.3809 & ** & $\mathrm{C} 26 \mathrm{H} 55 \mathrm{NO} 6 \mathrm{P}$ \\
\hline LPC $(O-18: 1) / L P C(P-18: 0)+2 O$ & 540.3665 & 540.3662 & -0.6144 & $* *$ & C26H55NO8P \\
\hline LPC $(0-20: 0)$ & 538.4237 & 538.4238 & 0.2749 & ** & $\mathrm{C} 28 \mathrm{H} 61 \mathrm{NO} 6 \mathrm{P}$ \\
\hline LPC(P-18:1) & 506.3611 & 506.3606 & -0.8926 & ** & $\mathrm{C} 26 \mathrm{H} 53 \mathrm{NO} 6 \mathrm{P}$ \\
\hline $\operatorname{LPC}(\mathrm{P}-20: 0)$ & 536.4080 & 536.4075 & -0.9359 & $* *$ & $\mathrm{C} 28 \mathrm{H} 59 \mathrm{NO} 6 \mathrm{P}$ \\
\hline \multicolumn{6}{|c|}{ SM identified as $[\mathrm{M}+\mathrm{H}]^{+}$} \\
\hline$S M(d 30: 0)$ & 649.5285 & 649.5258 & -2.5418 & * & $\mathrm{C} 35 \mathrm{H} 74 \mathrm{~N} 2 \mathrm{O} 6 \mathrm{P}$ \\
\hline$S M(d 30: 1)$ & 647.5128 & 647.5124 & -0.6193 & ** & $\mathrm{C} 35 \mathrm{H} 72 \mathrm{~N} 2 \mathrm{O} 6 \mathrm{P}$ \\
\hline$S M(d 32: 0)$ & 677.5598 & 677.5587 & -1.5512 & $* *$ & $\mathrm{C} 37 \mathrm{H} 78 \mathrm{~N} 2 \mathrm{O} 6 \mathrm{P}$ \\
\hline $\mathrm{SM}(\mathrm{d} 32: 1)$ & 675.5441 & 675.5435 & -0.8897 & $* *$ & $\mathrm{C} 37 \mathrm{H} 76 \mathrm{~N} 2 \mathrm{O} 6 \mathrm{P}$ \\
\hline $\mathrm{SM}(\mathrm{d} 32: 2)$ & 673.5285 & 673.5281 & -0.5211 & $* *$ & $\mathrm{C} 37 \mathrm{H} 74 \mathrm{~N} 2 \mathrm{O} 6 \mathrm{P}$ \\
\hline $\mathrm{SM}(\mathrm{d} 34: 0)$ & 705.5911 & 705.5894 & -2.3399 & $* *$ & $\mathrm{C} 39 \mathrm{H} 82 \mathrm{~N} 2 \mathrm{O} 6 \mathrm{P}$ \\
\hline
\end{tabular}




\begin{tabular}{|c|c|c|c|c|c|}
\hline $\operatorname{SM}(\mathrm{d} 34: 1)$ & 703.5754 & 703.5742 & -1.7070 & $(d 18: 1 / 16: 0)$ & C39H80N2O6P \\
\hline $\operatorname{SM}(\mathrm{d} 34: 2)$ & 701.5598 & 701.5581 & -2.3533 & $(d 18: 2 / 16: 0)$ & $\mathrm{C} 39 \mathrm{H} 78 \mathrm{~N} 2 \mathrm{O} 6 \mathrm{P}$ \\
\hline SM(d36:0) & 733.6224 & 733.6206 & -2.3868 & ** & $\mathrm{C} 41 \mathrm{H} 86 \mathrm{~N} 2 \mathrm{O} 6 \mathrm{P}$ \\
\hline $\operatorname{SM}(\mathrm{d} 36: 1)$ & 731.6067 & 731.6055 & -1.6416 & ** & $\mathrm{C} 41 \mathrm{H} 84 \mathrm{~N} 2 \mathrm{O} 6 \mathrm{P}$ \\
\hline SM(d36:2) & 729.5911 & 729.5902 & -1.1664 & ** & $\mathrm{C} 41 \mathrm{H} 82 \mathrm{~N} 2 \mathrm{O} 6 \mathrm{P}$ \\
\hline $\operatorname{SM}(d 36: 3)$ & 727.5754 & 727.5734 & -2.7502 & ** & $\mathrm{C} 41 \mathrm{H} 80 \mathrm{~N} 2 \mathrm{O} 6 \mathrm{P}$ \\
\hline $\operatorname{SM}(\mathrm{d} 38: 1)$ & 759.6380 & 759.6367 & -1.7127 & $(d 18: 1 / 20: 0)$ & $\mathrm{C} 43 \mathrm{H} 88 \mathrm{~N} 2 \mathrm{O} 6 \mathrm{P}$ \\
\hline SM(d38:2) & 757.6224 & 757.6209 & -1.9152 & ** & $\mathrm{C} 43 \mathrm{H} 86 \mathrm{~N} 2 \mathrm{O} 6 \mathrm{P}$ \\
\hline SM(d38:3) & 755.6067 & 755.6056 & -1.4571 & ** & $\mathrm{C} 43 \mathrm{H} 84 \mathrm{~N} 2 \mathrm{O} 6 \mathrm{P}$ \\
\hline $\operatorname{SM}(d 40: 1)$ & 787.6693 & 787.6672 & -2.6674 & ** & $\mathrm{C} 45 \mathrm{H} 92 \mathrm{~N} 2 \mathrm{O} 6 \mathrm{P}$ \\
\hline $\operatorname{SM}(d 40: 2)$ & 785.6537 & 785.6526 & -1.3377 & ** & $\mathrm{C} 45 \mathrm{H} 90 \mathrm{~N} 2 \mathrm{O} 6 \mathrm{P}$ \\
\hline $\operatorname{SM}(d 40: 3)$ & 783.6380 & 783.6365 & -1.9154 & ** & $\mathrm{C} 45 \mathrm{H} 88 \mathrm{~N} 2 \mathrm{O} 6 \mathrm{P}$ \\
\hline $\mathrm{SM}(\mathrm{d} 42: 2)$ & 813.6850 & 813.6835 & -1.7832 & ** & $\mathrm{C} 47 \mathrm{H} 94 \mathrm{~N} 2 \mathrm{O} 6 \mathrm{P}$ \\
\hline $\mathrm{SM}(\mathrm{d} 42: 3)$ & 811.6693 & 811.6682 & -1.3565 & $* *$ & $\mathrm{C} 47 \mathrm{H} 92 \mathrm{~N} 2 \mathrm{O} 6 \mathrm{P}$ \\
\hline SM(d44:2) & 841.7163 & 841.7141 & -2.5555 & * & $\mathrm{C} 49 \mathrm{H} 98 \mathrm{~N} 2 \mathrm{O} 6 \mathrm{P}$ \\
\hline
\end{tabular}

\section{PE identified as [M - $\mathrm{H}^{-}$}

(confirmation of polar head group by MS/MS of $[\mathrm{M}+\mathrm{H}]^{+}$)

\begin{tabular}{|c|c|c|c|c|c|}
\hline $\mathrm{PE}(30: 0)$ & 662.4760 & 662.4763 & 0.4528 & * & C35H69NO8P \\
\hline $\mathrm{PE}(32: 1)$ & 688.4917 & 688.4929 & 1.6965 & * & $\mathrm{C} 37 \mathrm{H} 71 \mathrm{NO} 8 \mathrm{P}$ \\
\hline $\mathrm{PE}(34: 1)$ & 716.5230 & 716.5223 & -0.9769 & $(16: 0 / 18: 1)$ & $\mathrm{C} 39 \mathrm{H} 75 \mathrm{NO} 8 \mathrm{P}$ \\
\hline $\mathrm{PE}(34: 2)$ & 714.5070 & 714.5081 & 1.5395 & $(16: 0 / 18: 2)$ & C39H73NO8P \\
\hline $\mathrm{PE}(34: 3)$ & 712.4920 & 712.4924 & 0.5614 & ** & $\mathrm{C} 39 \mathrm{H} 71 \mathrm{O} 8 \mathrm{NP}$ \\
\hline $\mathrm{PE}(36: 2)$ & 742.5387 & 742.5398 & 1.4814 & (18:0/18:2) and (18:1/18:1) & $\mathrm{C} 41 \mathrm{H} 77 \mathrm{NO} 8 \mathrm{P}$ \\
\hline $\operatorname{PE}(36: 3)$ & 740.5230 & 740.5255 & 3.3760 & $(18: 1 / 18: 2)$ & $\mathrm{C} 41 \mathrm{H} 75 \mathrm{NO} 8 \mathrm{P}$ \\
\hline$P E(36: 4)+O$ & 754.5023 & 754.5035 & 1.5944 & * & C41H73NO9P \\
\hline $\mathrm{PE}(38: 4)$ & 766.5390 & 766.5390 & 0.0000 & $(18: 0 / 20: 4)$ & C43H77O8NP \\
\hline $\mathrm{PE}(38: 5)$ & 764.5230 & 764.5219 & -1.4388 & $(18: 1 / 20: 4)$ & $\mathrm{C} 43 \mathrm{H} 75 \mathrm{NO} 8 \mathrm{P}$ \\
\hline $\operatorname{PE}(38: 6)$ & 762.507 & 762.5082 & 1.5738 & $(16: 0 / 22: 6)$ & $\mathrm{C} 43 \mathrm{H} 73 \mathrm{O} 8 \mathrm{NP}$ \\
\hline$P E(40: 4)+O$ & 810.5649 & 810.5625 & -2.9572 & ** & C45H81NO9P \\
\hline $\operatorname{PE}(40: 6)$ & 790.5300 & 790.5263 & -0.1265 & $(18: 0 / 22: 6)$ & C45H77O8NP \\
\hline $\mathrm{PE}(40: 7)$ & 788.5230 & 788.5235 & 0.6341 & $(18: 1 / 22: 6)$ & $\mathrm{C} 45 \mathrm{H} 75 \mathrm{NO} 8 \mathrm{P}$ \\
\hline $\operatorname{PE}(40: 8)$ & 786.5070 & 786.5078 & 1.0172 & ** & $\mathrm{C} 45 \mathrm{H} 73 \mathrm{O} 8 \mathrm{NP}$ \\
\hline $\mathrm{PE}(\mathrm{P}-34: 0) / \mathrm{PE}(\mathrm{O}-34: 1)$ & 702.5440 & 702.5447 & 0.9964 & * & C39H77NO7P \\
\hline $\mathrm{PE}(\mathrm{P}-34: 1) / \mathrm{PE}(\mathrm{O}-34: 2)$ & 700.5280 & 700.5289 & 1.2847 & $\begin{array}{l}\text { (O-16:0/18:2), (O-16:1/18:1) and/or } \\
\text { (P-16:0/18:1) and/or (P-18:1/16:0) }\end{array}$ & C39H75NO7P \\
\hline $\mathrm{PE}(\mathrm{P}-34: 2) / \mathrm{PE}(\mathrm{O}-34: 3)$ & 698.5130 & 698.5143 & 1.8611 & (P-16:0/18:2) and/or (O-16:1/18:2) & C39H73NO7P \\
\hline $\mathrm{PE}(\mathrm{P}-36: 1) / \mathrm{PE}(\mathrm{O}-36: 2)$ & 728.5590 & 728.5585 & -0.6863 & $\begin{array}{l}(\mathrm{O}-18: 0 / 18: 2),(\mathrm{P}-18: 0 / 18: 1) \text { and/or } \\
(\mathrm{O}-18: 1 / 18: 1)\end{array}$ & C41H79NO7P \\
\hline $\mathrm{PE}(\mathrm{P}-36: 2) / \mathrm{PE}(\mathrm{O}-36: 3)$ & 726.5440 & 726.5455 & 2.0646 & $\begin{array}{l}(P-18: 1 / 18: 1),(P-18: 0 / 18: 2) \text { and/or } \\
(\mathrm{O}-18: 1 / 18: 2)\end{array}$ & C41H77NO7P \\
\hline $\mathrm{PE}(\mathrm{P}-36: 3) / \mathrm{PE}(\mathrm{O}-36: 4)$ & 724.5280 & 724.529 & 1.3802 & $(\mathrm{P}-18: 1 / 18: 2)$ and $(\mathrm{O}-16: 0 / 20: 4)$ & C41H75NO7P \\
\hline $\mathrm{PE}(\mathrm{P}-36: 4) / \mathrm{PE}(\mathrm{O}-36: 5)$ & 722.5130 & 722.5142 & 1.6609 & $(\mathrm{P}-16: 0 / 20: 4)$ and/or (O-16:1/20:4) & C41H73NO7P \\
\hline $\mathrm{PE}(\mathrm{P}-38: 3) / \mathrm{PE}(\mathrm{O}-38: 4)$ & 752.5590 & 752.5576 & -1.8603 & $\begin{array}{l}(\mathrm{O}-18: 0 / 20: 4),(\mathrm{P}-18: 0 / 20: 3) \text { and/or } \\
(\mathrm{O}-18: 1 / 20: 3)\end{array}$ & C43H79NO7P \\
\hline $\mathrm{PE}(\mathrm{P}-38: 4) / \mathrm{PE}(\mathrm{O}-38: 5)$ & 750.5440 & 750.544 & 0.0000 & $(\mathrm{P}-18: 0 / 20: 4)$ and/or (O-18:1/20:4) & C43H77NO7P \\
\hline $\mathrm{PE}(\mathrm{P}-38: 5) / \mathrm{PE}(\mathrm{O}-38: 6)$ & 748.5280 & 748.5281 & 0.1336 & $(P-18: 1 / 20: 4)$ & C43H75NO7P \\
\hline $\mathrm{PE}(\mathrm{P}-40: 4) / \mathrm{PE}(\mathrm{O}-40: 5)$ & 778.5750 & 778.5729 & -2.6972 & * & C45H81NO7P \\
\hline$P E(P-36: 6)$ & 718.4810 & 718.4829 & 2.6445 & ** & $\mathrm{C} 41 \mathrm{H} 69 \mathrm{O} 7 \mathrm{NP}$ \\
\hline
\end{tabular}

LPE identified as [M - H] 
(confirmation of polar head group by MS/MS of $[\mathrm{M}+\mathrm{H}]^{+}$)

\begin{tabular}{|c|c|c|c|c|c|}
\hline LPE(18:4) & 472.2464 & 472.2464 & -0.0339 & * & C23H39NO7P \\
\hline \multicolumn{6}{|c|}{ PG identified as [M - H] } \\
\hline PG(18:0/C5aldehyde) & 609.3404 & 609.3419 & 2.4978 & * & $\mathrm{C} 29 \mathrm{H} 54011 \mathrm{P}$ \\
\hline$P G(26: 0)$ & 637.4081 & 637.4092 & 1.7257 & $(12: 0 / 14: 0)$ & $\mathrm{C} 32 \mathrm{H} 62 \mathrm{O} 10 \mathrm{P}$ \\
\hline$P G(30: 0)$ & 693.4707 & 693.4701 & -0.8652 & $(14: 0 / 16: 0)$ & $\mathrm{C} 36 \mathrm{H} 70 \mathrm{O} 10 \mathrm{P}$ \\
\hline$P G(36: 7)$ & 763.4550 & 763.4588 & 1.9648 & * & $\mathrm{C} 42 \mathrm{H} 68 \mathrm{O} 10 \mathrm{P}$ \\
\hline $\mathrm{PG}(36: 6)$ & 765.4707 & 765.4713 & 0.7838 & * & $\mathrm{C} 42 \mathrm{H} 70010 \mathrm{P}$ \\
\hline$P G(36: 3)$ & 771.5176 & 771.5192 & 2.0738 & * & $\mathrm{C} 42 \mathrm{H} 76 \mathrm{O} 10 \mathrm{P}$ \\
\hline$P G(36: 2)$ & 773.5333 & 773.5332 & -0.1293 & $(18: 0 / 18: 2)$ & $\mathrm{C} 42 \mathrm{H} 80 \mathrm{O} 10 \mathrm{P}$ \\
\hline$P G(36: 1)$ & 775.5489 & 775.5471 & -2.3209 & $(18: 0 / 18: 1)$ & $\mathrm{C} 42 \mathrm{H} 80010 \mathrm{P}$ \\
\hline $\operatorname{LPG}(14: 0)$ & 455.2410 & 455.2424 & 3.0797 & $(14: 0)$ & $\mathrm{C} 2 \mathrm{OH} 40 \mathrm{O} 9 \mathrm{P}$ \\
\hline $\operatorname{LPG}(16: 1)$ & 481.2566 & 481.258 & 2.8093 & * & $\mathrm{C} 22 \mathrm{H} 42 \mathrm{O} 9 \mathrm{P}$ \\
\hline $\operatorname{LPG}(16: 0)$ & 483.2723 & 483.2734 & 2.2803 & * & $\mathrm{C} 22 \mathrm{H} 44 \mathrm{O} 9 \mathrm{P}$ \\
\hline LPG(18:2) & 507.2723 & 507.2730 & 1.3839 & * & $\mathrm{C} 24 \mathrm{H} 4409 \mathrm{P}$ \\
\hline $\operatorname{LPG}(18: 1)$ & 509.2879 & 509.2891 & 2.2620 & $(18: 1)$ & $\mathrm{C} 24 \mathrm{H} 4609 \mathrm{P}$ \\
\hline \multicolumn{6}{|c|}{ PI identified as [M - H] $]^{-}$} \\
\hline $\mathrm{PI}(34: 2)$ & 833.5180 & 833.5184 & 0.4799 & * & $\mathrm{C} 43 \mathrm{H} 78 \mathrm{O} 13 \mathrm{P}$ \\
\hline $\mathrm{Pl}(34: 1)$ & 835.5337 & 835.5337 & 0.0000 & * & C43H80013P \\
\hline $\mathrm{PI}(36: 4)$ & 857.5180 & 857.5173 & -0.8163 & $(16: 0 / 20: 4)$ & $\mathrm{C} 45 \mathrm{H} 78 \mathrm{O} 13 \mathrm{P}$ \\
\hline$P S(30: 3)$ & 700.4190 & 700.4182 & -1.1422 & * & C36H63NO10P \\
\hline$P S(38: 6)$ & 806.4972 & 806.5000 & 3.4718 & * & C44H73NO10P \\
\hline PS(38:4) & 810.5285 & 810.5304 & 2.3441 & * & C44H77NO10P \\
\hline PS(40:6) & 834.5285 & 834.5308 & 2.7560 & * & $\mathrm{C} 46 \mathrm{H} 77 \mathrm{NO10P}$ \\
\hline
\end{tabular}


Supplementary Table S4. The 146 lipid species showing significant variation between PKU and control (CT) groups, ordered by increasing values of $q$-value ${ }^{*}$ if $q<0.05$, ${ }^{* *}$ if $q<0.01$ and ${ }^{* * *}$ if $q<0.001 ; \uparrow$ if increased and $\downarrow$ if decreased in PKU group). Lipid species are labelled as follows: AAAA (xx:i) (AAAA=lipid class abbreviation; $x x=$ number of carbon atoms in fatty acid(s); $i=$ number of double bonds). The 'O-' prefix is used for plasmanyl species to indicate the presence of an alkyl ether substituent, whereas the 'P-' prefix is used for plasmenyl species to indicate the alk-1-enyl ether substituent. Lipid class abbreviations: PC, phosphatidylcholine; LPC, lysophosphatidylcholine; SM, sphingomyelin; PE, phosphatidylethanolamine; LPE, lysophosphatidylethanolamine; PG, phosphatidylglycerol; LPG, lysophosphatidylglycerol; PI, phosphatidylinositol; PS, phosphatidylserine.

\begin{tabular}{|c|c|c|c|}
\hline Lipid species (C:N) & FDR, $q$-value & $\begin{array}{c}\text { Statistical } \\
\text { significance } \\
\text { level }\end{array}$ & $\begin{array}{c}\text { Change } \\
\text { in PKU } \\
\text { group }\end{array}$ \\
\hline $\mathrm{PC}(40: 8)$ & $9.21 \mathrm{E}-12$ & $\star * \star$ & $\uparrow$ \\
\hline PC (44:12) & $2.23 \mathrm{E}-11$ & $* \star \star$ & $\uparrow$ \\
\hline PC (42:7) & $6.64 \mathrm{E}-11$ & $\star \star \star \star ~$ & $\uparrow$ \\
\hline $\mathrm{SM}(\mathrm{d} 34: 1)$ & 8.77E-10 & $\star * *$ & $\uparrow$ \\
\hline PS (38:4) & 4.13E-08 & $\star \star * \star$ & $\downarrow$ \\
\hline SM (d36:3) & 4.13E-08 & $\star * \star$ & $\uparrow$ \\
\hline PS (40:6) & $1.16 \mathrm{E}-07$ & $* * *$ & $\downarrow$ \\
\hline LPC (14:0) & $1.21 \mathrm{E}-07$ & $* \star *$ & $\uparrow$ \\
\hline PC (40:7) & $1.48 \mathrm{E}-07$ & $* * *$ & $\uparrow$ \\
\hline PS (38:6) & $1.48 \mathrm{E}-07$ & $\star \star \star \star ~$ & $\downarrow$ \\
\hline SM (d36:2) & $1.50 \mathrm{E}-07$ & $* * *$ & $\uparrow$ \\
\hline PC (44:11) & $6.06 \mathrm{E}-07$ & $\star \star \star \star ~$ & $\uparrow$ \\
\hline SM (d34:2) & $6.06 \mathrm{E}-07$ & $\star \star *$ & $\uparrow$ \\
\hline SM (d38:3) & $6.19 \mathrm{E}-07$ & $\star \star * *$ & $\uparrow$ \\
\hline PC (42:9) & $1.01 \mathrm{E}-06$ & $\star \star \star *$ & $\uparrow$ \\
\hline PC (40:5) & $1.01 \mathrm{E}-06$ & $* * *$ & $\uparrow$ \\
\hline PC (44:4) & $1.54 \mathrm{E}-06$ & $* * *$ & $\uparrow$ \\
\hline $\mathrm{PI}(38: 4)$ & 2.27E-06 & $* * *$ & $\uparrow$ \\
\hline $\mathrm{PC}(40: 9)$ & 2.87E-06 & $* * *$ & $\uparrow$ \\
\hline $\mathrm{PC}(38: 5)$ & 2.94E-06 & $* \star *$ & $\uparrow$ \\
\hline PC (38:7) & 2.94E-06 & 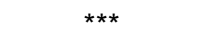 & $\uparrow$ \\
\hline PC (40:4) & 2.94E-06 & $* * \star$ & $\uparrow$ \\
\hline$P C(42: 4)$ & 2.94E-06 & $* * *$ & $\uparrow$ \\
\hline PI (36:4) & 2.94E-06 & $\star * *$ & $\uparrow$ \\
\hline SM (d32:2) & 2.94E-06 & $* * *$ & $\downarrow$ \\
\hline SM (d42:3) & $3.40 \mathrm{E}-06$ & $* * *$ & $\uparrow$ \\
\hline SM (d36:1) & 3.59E-06 & $* * *$ & $\uparrow$ \\
\hline $\mathrm{SM}(\mathrm{d} 32: 1)$ & 3.68E-06 & $* * *$ & $\uparrow$ \\
\hline PC (38:8) & $4.11 \mathrm{E}-06$ & $\star \star \star \star$ & $\uparrow$ \\
\hline LPC (22:0) & 4.49E-06 & $* * *$ & $\uparrow$ \\
\hline PC (34:3) & 4.49E-06 & $\star \star \star \star$ & $\uparrow$ \\
\hline SM (d36:0) & 4.49E-06 & $\star \star \star *$ & $\uparrow$ \\
\hline$P G(34: 1)$ & 4.83E-06 & $\star \star * *$ & $\uparrow$ \\
\hline PC (32:2) & 5.00E-06 & 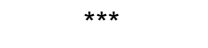 & $\uparrow$ \\
\hline LPC (20:0) & 5.52E-06 & $* * *$ & $\uparrow$ \\
\hline LPC (P-18:1) & 5.52E-06 & $* * *$ & $\uparrow$ \\
\hline PC (34:4) & 5.52E-06 & $* * *$ & $\uparrow$ \\
\hline PC (42:5) & 5.52E-06 & $\star \star * *$ & $\uparrow$ \\
\hline PC (42:6) & $6.85 E-06$ & $\star * \star$ & $\uparrow$ \\
\hline $\operatorname{LPC}(18: 0)$ & $7.25 \mathrm{E}-06$ & 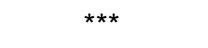 & $\uparrow$ \\
\hline PE (P-34:1)/PE (O-34:2) & 1.17E-05 & $\star * \star$ & $\uparrow$ \\
\hline$P G(36: 1)$ & 1.17E-05 & $* * *$ & $\uparrow$ \\
\hline PC (36:6) & $1.79 \mathrm{E}-05$ & 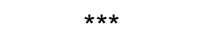 & $\uparrow$ \\
\hline $\mathrm{PC}(40: 4)+\mathrm{O}$ & $1.79 \mathrm{E}-05$ & $* * *$ & $\uparrow$ \\
\hline PC (36:3) & 1.83E-05 & $* * *$ & $\uparrow$ \\
\hline $\operatorname{LPC}(16: 1)+\mathrm{O}$ & $1.96 \mathrm{E}-05$ & $* * *$ & $\downarrow$ \\
\hline
\end{tabular}




\begin{tabular}{|c|c|}
\hline LPC (16:1) & 2.51E-05 \\
\hline LPC $(24: 0)$ & 2.53E-05 \\
\hline $\mathrm{PI}(40: 6)$ & 2.53E-05 \\
\hline SM (d40:3) & 2.97E-05 \\
\hline PC (44:9) & 3.16E-05 \\
\hline $\mathrm{PC}(32: 1)$ & 3.26E-05 \\
\hline PC $(30: 1)$ & 3.82E-05 \\
\hline PE (P-38:5)/PE (O-38:6) & 3.82E-05 \\
\hline $\operatorname{LPC}(16: 0)$ & 4.17E-05 \\
\hline PC (44:8) & 4.17E-05 \\
\hline SM (d38:2) & 4.17E-05 \\
\hline PC (44:5) & 4.24E-05 \\
\hline SM (d44:2) & 4.29E-05 \\
\hline PC (42:10) & 4.44E-05 \\
\hline SM (d34:0) & $5.00 \mathrm{E}-05$ \\
\hline SM (d40:1) & 5.00E-05 \\
\hline LPC (18:1) & 5.56E-05 \\
\hline LPC (O-18:0) & 5.56E-05 \\
\hline PC (42:8) & 6.94E-05 \\
\hline LPC (22:1) & 7.52E-05 \\
\hline$P C(P-40: 6)$ & 7.53E-05 \\
\hline PE (P-36:1)/PE (O-36:2) & 7.53E-05 \\
\hline SM $(d 30: 1)$ & 7.53E-05 \\
\hline LPC (20:3) & $9.80 \mathrm{E}-05$ \\
\hline SM (d38:1) & $1.08 \mathrm{E}-04$ \\
\hline PC (44:10) & $1.11 \mathrm{E}-04$ \\
\hline LPC (18:3) & $1.42 \mathrm{E}-04$ \\
\hline$P G(36: 2)$ & $1.42 E-04$ \\
\hline PE (32:1) & 1.46E-04 \\
\hline PE (36:2) & 1.46E-04 \\
\hline LPC $(0-16: 0)$ & $1.51 \mathrm{E}-04$ \\
\hline LPC (20:2) & 1.73E-04 \\
\hline PE $(36: 3)$ & 2.66E-04 \\
\hline LPC (O-18:1)/LPC (P-18:0) & 2.79E-04 \\
\hline SM $(d 40: 2)$ & 2.79E-04 \\
\hline $\mathrm{PC}(\mathrm{O}-40: 4) / \mathrm{PC}(\mathrm{P}-40: 3)$ & 3.21E-04 \\
\hline $\operatorname{LPC}(22: 5)$ & 3.91E-04 \\
\hline PE (P-34:0)/PE (O-34:1) & 5.36E-04 \\
\hline PE (P-38:4)/PE (O-38:5) & 5.47E-04 \\
\hline$P C(30: 0)$ & $5.50 \mathrm{E}-04$ \\
\hline PE (38:5) & 5.67E-04 \\
\hline PC (34:5) & 5.88E-04 \\
\hline SM (d42:2) & $5.88 E-04$ \\
\hline PC (38:2) & 7.77E-04 \\
\hline $\mathrm{PE}(40: 4)+\mathrm{O}$ & 7.77E-04 \\
\hline $\mathrm{PC}(42: 11)$ & 8.08E-04 \\
\hline PS (30:3) & 8.37E-04 \\
\hline PC (O-28:0) & 8.63E-04 \\
\hline PE (P-36:3)/PE (O-36:4) & 8.63E-04 \\
\hline LPC (O-16:1)/LPC (P-16:0) & 9.45E-04 \\
\hline $\mathrm{PI}(34: 1)$ & 9.45E-04 \\
\hline LPC (20:4) & $1.03 E-03$ \\
\hline LPG (18:2) & 1.05E-03 \\
\hline LPC (18:3)+O & 1.22E-03 \\
\hline LPC (22:6) & $1.22 \mathrm{E}-03$ \\
\hline PC (40:10) & $1.22 \mathrm{E}-03$ \\
\hline PC (36:4) & 1.39E-03 \\
\hline PC (32:0) & $1.53 E-03$ \\
\hline
\end{tabular}




\begin{tabular}{|c|c|c|c|}
\hline$P C(40: 5)+20$ & $1.53 \mathrm{E}-03$ & ** & $\uparrow$ \\
\hline PE (34:3) & $1.59 \mathrm{E}-03$ & ** & $\uparrow$ \\
\hline $\mathrm{PC}(32: 1)+\mathrm{O}$ & $1.97 \mathrm{E}-03$ & ** & $\uparrow$ \\
\hline PE (34:2) & $2.09 \mathrm{E}-03$ & ** & $\uparrow$ \\
\hline $\mathrm{PE}(\mathrm{P}-34: 2) / \mathrm{PE}(\mathrm{O}-34: 3)$ & $2.14 \mathrm{E}-03$ & ** & $\uparrow$ \\
\hline LPC $(18: 2)+20$ & 2.17E-03 & ** & $\downarrow$ \\
\hline PE (38:4) & $2.35 \mathrm{E}-03$ & ** & $\uparrow$ \\
\hline PE (P-38:3)/PE (O-38:4) & $2.35 \mathrm{E}-03$ & ** & $\uparrow$ \\
\hline PE (P-40:4)/PE (O-40:5) & $3.01 \mathrm{E}-03$ & ** & $\uparrow$ \\
\hline PC (O-34:1)/PC (P-34:0) & $3.08 \mathrm{E}-03$ & ** & $\uparrow$ \\
\hline PE $(40: 7)$ & $3.49 \mathrm{E}-03$ & ** & $\uparrow$ \\
\hline LPC $(20: 1)$ & $4.24 \mathrm{E}-03$ & ** & $\uparrow$ \\
\hline $\mathrm{PC}(36: 2)$ & 4.41E-03 & ** & $\uparrow$ \\
\hline PC (34:2) & $5.21 \mathrm{E}-03$ & ** & $\uparrow$ \\
\hline LPE (18:4) & $5.28 \mathrm{E}-03$ & ** & $\uparrow$ \\
\hline PC (O-38:4)/PC (P-38:3) & $6.11 \mathrm{E}-03$ & ** & $\uparrow$ \\
\hline LPC (22:4) & $6.64 \mathrm{E}-03$ & ** & $\uparrow$ \\
\hline LPC (18:2) & 7.04E-03 & ** & $\uparrow$ \\
\hline PI (36:2) & 7.33E-03 & ** & $\uparrow$ \\
\hline $\mathrm{PC}(\mathrm{O}-40: 5) / \mathrm{PC}(\mathrm{P}-40: 4)$ & 7.56E-03 & ** & $\uparrow$ \\
\hline $\mathrm{PI}(36: 1)$ & 7.76E-03 & ** & $\uparrow$ \\
\hline PC (36:5) & $8.64 \mathrm{E}-03$ & ** & $\uparrow$ \\
\hline $\mathrm{PC}(40: 6)$ & 8.64E-03 & ** & $\uparrow$ \\
\hline PI (36:3) & 8.64E-03 & ** & $\uparrow$ \\
\hline PE (P-36:6) & $8.81 \mathrm{E}-03$ & ** & $\downarrow$ \\
\hline LPG $(16: 1)$ & $9.31 \mathrm{E}-03$ & ** & $\uparrow$ \\
\hline PC (38:6) & $9.95 \mathrm{E}-03$ & ** & $\uparrow$ \\
\hline$P G(36: 3)$ & $1.13 \mathrm{E}-02$ & * & $\uparrow$ \\
\hline $\mathrm{PE}(\mathrm{P}-36: 2) / \mathrm{PE}(\mathrm{O}-36: 3)$ & $1.24 \mathrm{E}-02$ & * & $\uparrow$ \\
\hline LPG $(18: 1)$ & $1.26 \mathrm{E}-02$ & * & $\uparrow$ \\
\hline LPC (O-18:1)/LPC (P-18:0)+2O & $1.31 \mathrm{E}-02$ & * & $\downarrow$ \\
\hline PC (O-38:3)/PC (P-38:2) & $1.50 \mathrm{E}-02$ & * & $\uparrow$ \\
\hline LPC $(20: 5)$ & $1.58 \mathrm{E}-02$ & * & $\uparrow$ \\
\hline PC $(34: 1)+O$ & $1.69 \mathrm{E}-02$ & * & $\downarrow$ \\
\hline LPC $(18: 1)+O$ & $1.78 \mathrm{E}-02$ & * & $\downarrow$ \\
\hline $\mathrm{PC}(\mathrm{O}-40: 6) / \mathrm{PC}(\mathrm{P}-40: 5)$ & $2.21 \mathrm{E}-02$ & * & $\uparrow$ \\
\hline PE $(34: 1)$ & 2.47E-02 & * & $\uparrow$ \\
\hline PC (O-38:5)/PC (P-38:4) & 2.55E-02 & * & $\uparrow$ \\
\hline$P G(30: 0)$ & 2.78E-02 & * & $\uparrow$ \\
\hline PC (O-38:6)/PC (P-38:5) & 2.95E-02 & * & $\uparrow$ \\
\hline$P G(36: 6)$ & $3.62 \mathrm{E}-02$ & * & $\uparrow$ \\
\hline PC (O-36:2)/PC (P-36:1) & 3.67E-02 & * & $\uparrow$ \\
\hline
\end{tabular}


A

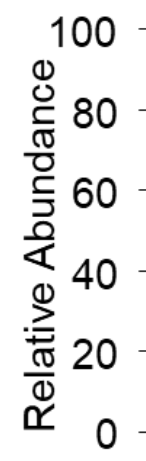

184.1<smiles>[R]C(=O)OC[C@@H](OC([R])=O)[C@@](C)(CC[R14]([R4])([R])[H])OP(=O)(O)OCC[N+](C)(C)C</smiles>

86.1125 .0 185.1 387.4

$[\mathrm{M}+\mathrm{H}]^{+}$<smiles>C1CC(C2CCC2)C1</smiles>

185.1

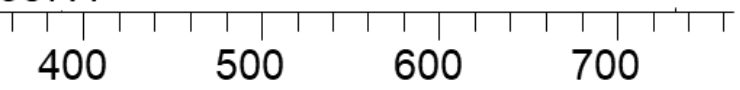

$\mathrm{m} / \mathrm{z}$

\section{B}

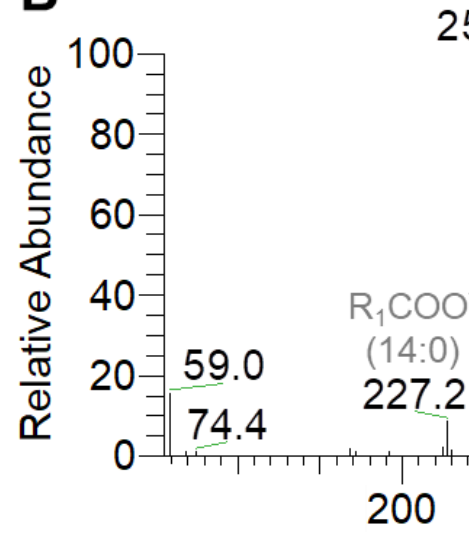

$\mathrm{R}_{2} \mathrm{COO}^{-}$

(16:1)

253.2

$\mathrm{m} / \mathrm{z}$

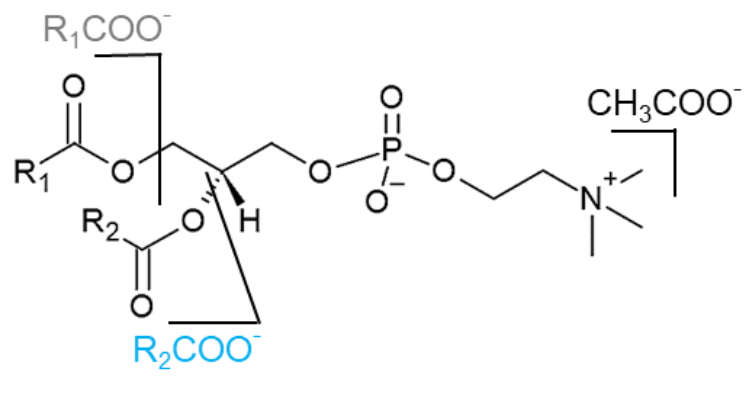

255.2

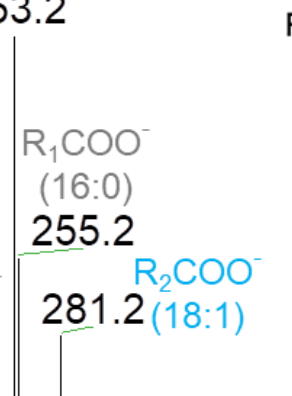

$281.2(18: 1)$ 

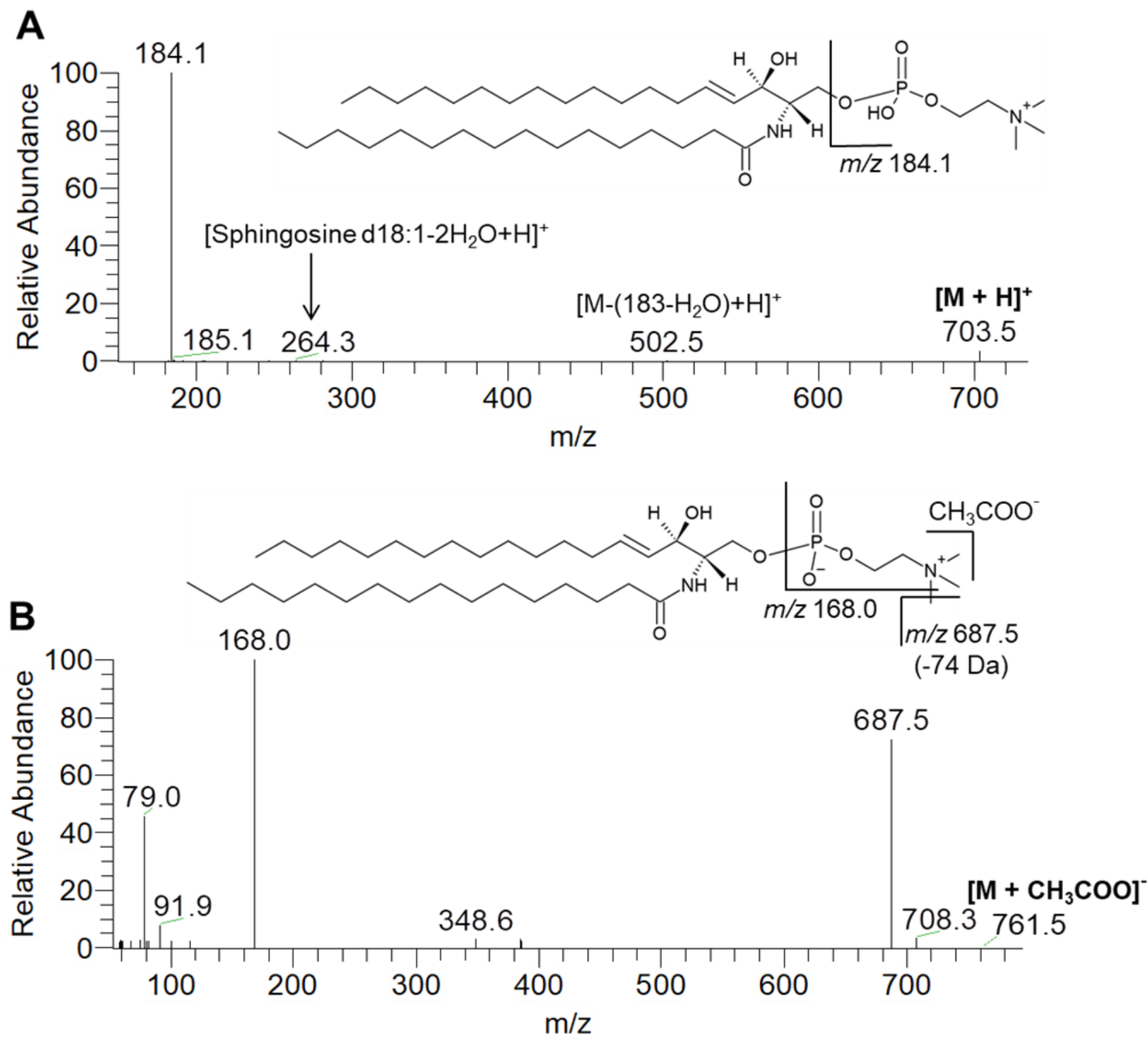

Supplementary Figure S2. Representative MS/MS spectra of sphingomyelin (SM) lipid species. A) HILIC-MS/MS spectrum of the lipid species SM (d34:1) observed in positive mode as $[\mathrm{M}+\mathrm{H}]^{+}$ion at $\mathrm{m} / \mathrm{z}$ 703.5. Confirmation of phospholipid class was achieved by the identification of the product ion at $\mathrm{m} / \mathrm{z} 184.1$ (formula: $\mathrm{C}_{5} \mathrm{H}_{15} \mathrm{NO}_{4} \mathrm{P}$; exact mass: 184.0739), corresponding to the phosphocholine polar head; and the product ion of sphingoid base at 264.3 , corresponding to [Sphingosine $\left.\mathrm{d} 18: 1-2 \mathrm{H}_{2} \mathrm{O}+\mathrm{H}\right]^{+}$. The mass difference of $238 \mathrm{Da}$ between the product ions at $\mathrm{m} / \mathrm{z} 502.5\left(\left[\mathrm{M}-\left(183-\mathrm{H}_{2} \mathrm{O}\right)+\mathrm{H}\right]^{+}\right)$and 264.3 , plus $18 \mathrm{Da}$, allowed to infer the presence of 16:0 as fatty acyl amide substituent. B) HILIC-MS/MS spectrum of the lipid species SM (d34:1) observed in negative mode as $\left[\mathrm{M}+\mathrm{CH}_{3} \mathrm{COO}\right]^{-}$ion at $\mathrm{m} / \mathrm{z}$ 761.5. Confirmation of phospholipid class was achieved by the identification of the product ion at $\mathrm{m} / \mathrm{z} 168.0$ (formula: $\mathrm{C}_{4} \mathrm{H}_{11} \mathrm{NO}_{4} \mathrm{P}$; exact mass:168.0425), corresponding to the phosphocholine polar head without a methyl group, and by observing the characteristic neutral loss of $74 \mathrm{Da}$ (formula: $\mathrm{C}_{3} \mathrm{H}_{6} \mathrm{O}_{2}$; exact mass: 74.0368 ), corresponding to the loss of methyl acetate. 


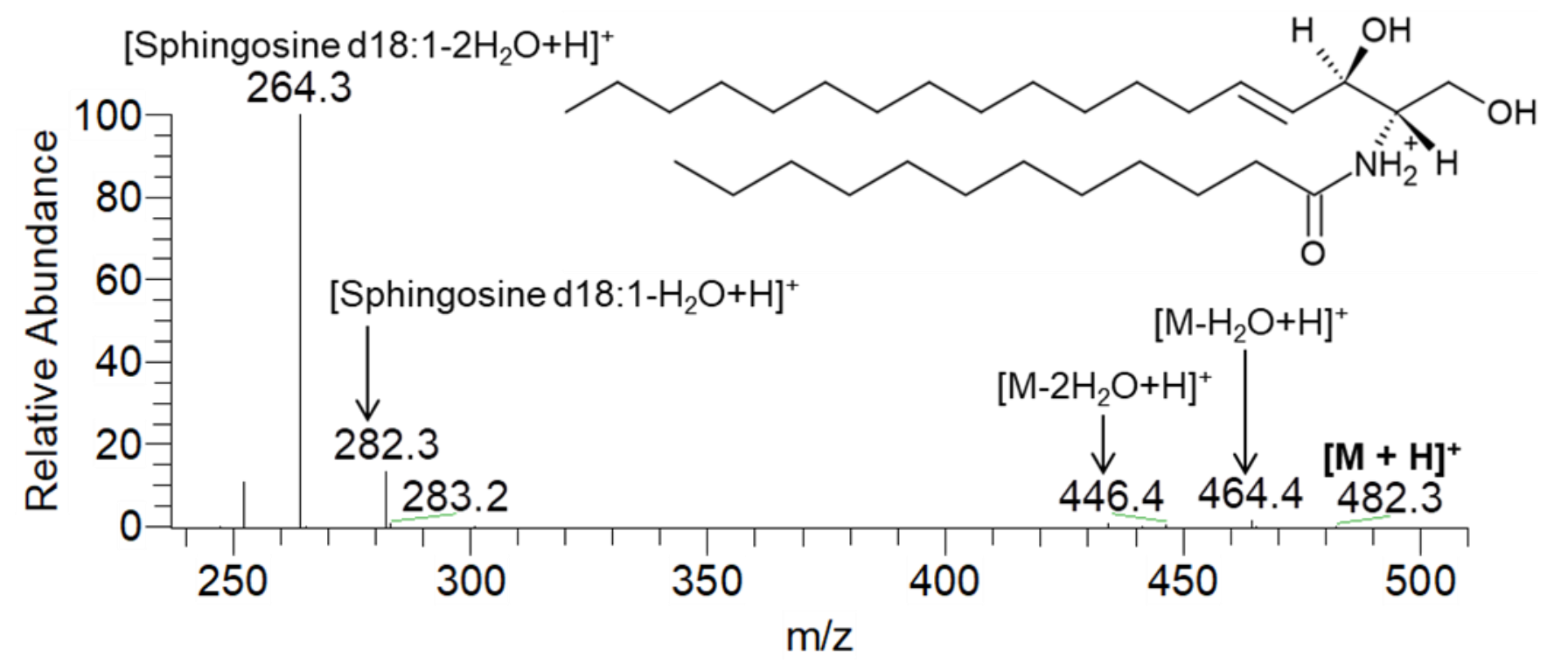

Supplementary Figure S3. Representative MS/MS spectrum of ceramide (Cer) lipid species. HILIC-MS/MS spectrum of the lipid species Cer (d30:1) observed in positive mode as $[\mathrm{M}+\mathrm{H}]^{+}$ion at $\mathrm{m} / \mathrm{z} 482.3$. Confirmation of phospholipid class was achieved by the identification of the abundant product ions of the sphingoid at $m / z 264.3$ and 282.3, corresponding to [Sphingosine d18:1$\left.2 \mathrm{H}_{2} \mathrm{O}+\mathrm{H}\right]^{+}$and [Sphingosine d18:1- $\left.\mathrm{H}_{2} \mathrm{O}+\mathrm{H}\right]^{+}$. The mass difference of $218 \mathrm{Da}$ between the product ions at $\mathrm{m} / \mathrm{z} 446.4([\mathrm{M}-$ $\left.2 \mathrm{H}_{2} \mathrm{O}+\mathrm{H}\right]^{+}$) and 264.3 , plus $18 \mathrm{Da}$, allowed to infer the presence of $12: 0$ as fatty acyl amide substituent. 
A

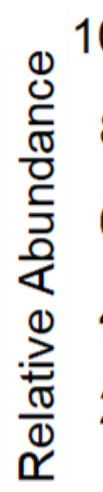

100

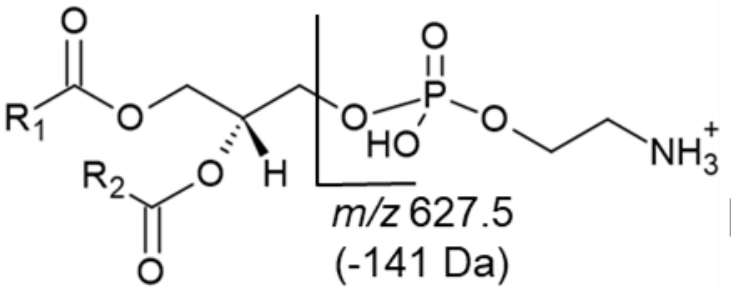

(-141 Da)

$[\mathrm{M}+\mathrm{H}]^{+}$

768.5

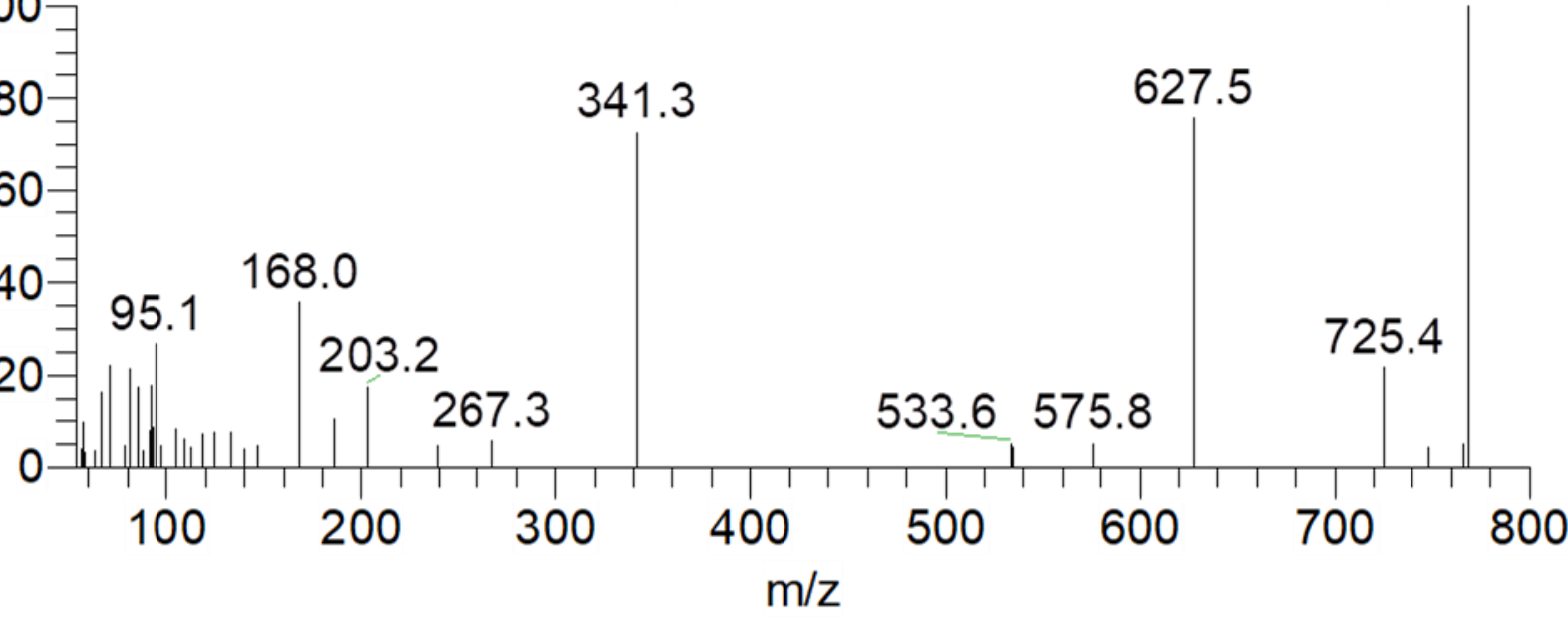

B

$\mathrm{R}_{2} \mathrm{COO}^{-}$

造

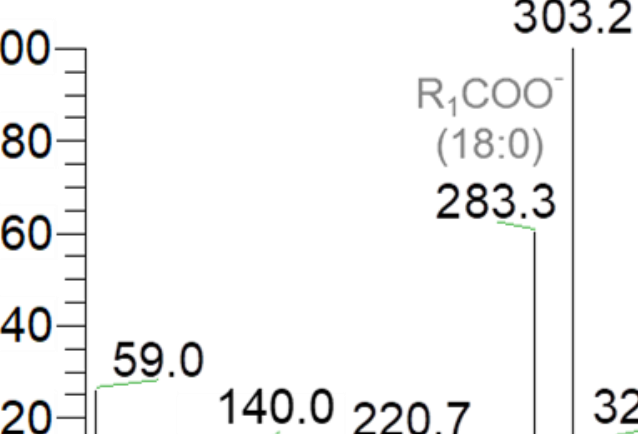

$325.2 \quad 434.6$

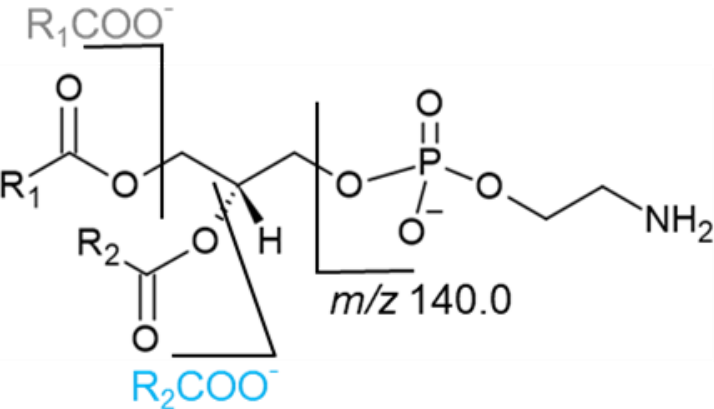

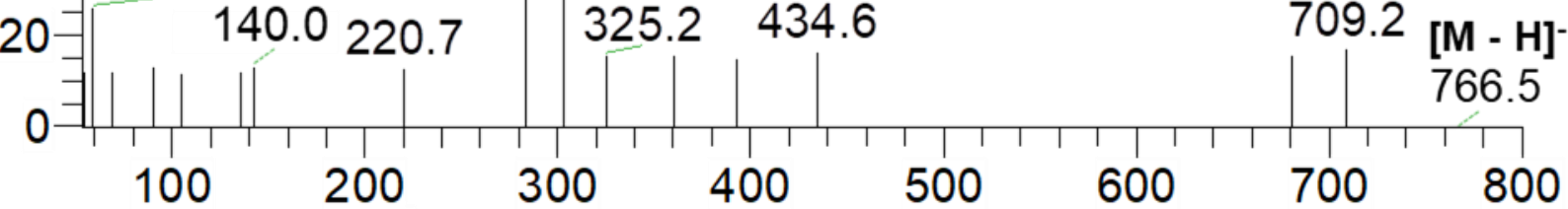

$\mathrm{m} / \mathrm{z}$

Supplementary Figure S4. Representative MS/MS spectra of phosphatidylethanolamine (PE) lipid species. A) HILIC-MS/MS spectrum of the lipid species PE (38:4) observed in positive mode as $[\mathrm{M}+\mathrm{H}]^{+}$ion at $\mathrm{m} / \mathrm{z} 768.5$. Confirmation of phospholipid class was achieved by the identification of the neutral loss of $141 \mathrm{Da}$ (formula: $\mathrm{C}_{2} \mathrm{H}_{8} \mathrm{NO}_{4} \mathrm{P}$; exact mass: 141.0191), corresponding to phosphoethanolamine polar head. B) HILIC-MS/MS spectrum of the lipid species PE (38:4) observed in negative mode as [M - $\mathrm{H}^{-}$at $\mathrm{m} / \mathrm{z}$ 766.5. Fatty acid composition was confirmed by the identification of product ions corresponding to the fatty acyl chains as [RCOO]. The product ions observed at $\mathrm{m} / \mathrm{z} 283.3$ and 303.2 , corresponding to fatty acyl carboxylate anions of $18: 0$ $\left(\mathrm{R}_{1} \mathrm{COO}^{-}\right)$and 20:4 ( $\left.\mathrm{R}_{2} \mathrm{COO}^{-}\right)$, allowed to identify the fatty acyl composition of PE (18:0/20:4). The confirmation as PE species was also achieved by observing the product ion at $\mathrm{m} / \mathrm{z} 140.0$ (formula: $\mathrm{C}_{2} \mathrm{H}_{7} \mathrm{NO}_{4} \mathrm{P}$; exact mass: 140.0113), corresponding to phosphoethanolamine polar head. For LPE, the same fragmentation was observed, with the exception that only one product ion corresponding to a fatty acid was detected. 


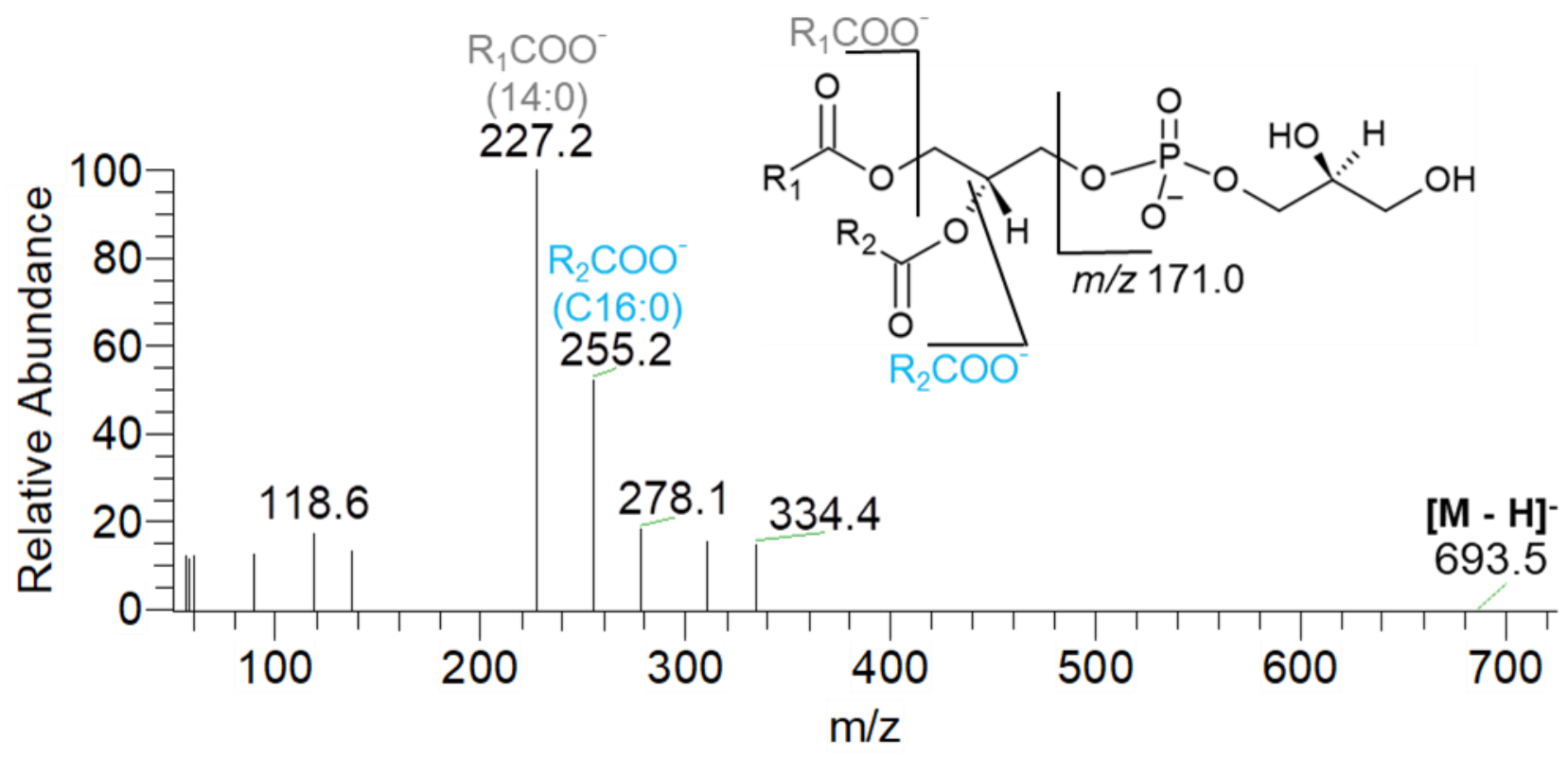

Supplementary Figure S5. Representative MS/MS spectrum of phosphatidylglycerol (PG) lipid species. HILIC-MS/MS spectrum of the lipid species PG (30:0) observed in negative mode as $[\mathrm{M}-\mathrm{H}]^{-}$ion at $\mathrm{m} / \mathrm{z} 693.5$. Confirmation of phospholipid class may be achieved by the identification of the product ion at $\mathrm{m} / \mathrm{z} 171.0$ (formula: $\mathrm{C}_{3} \mathrm{H}_{8} \mathrm{O}_{6} \mathrm{P}$; exact mass: 171.0058), corresponding to the glycerol phosphate anion (not visible from molecular ions with low intensity, as occurred in this study). Fatty acid composition was confirmed by the identification of product ions corresponding to the fatty acyl chains as [RCOO]'. The product ions observed at $\mathrm{m} / \mathrm{z} 227.2$ and 255.2 , corresponding to fatty acyl carboxylate anions $14: 0$ (R $\mathrm{R}_{1} \mathrm{COO} \mathrm{O}^{-}$) and $16: 0$ $\left(\mathrm{R}_{2} \mathrm{COO}^{-}\right)$allowed to identify the fatty acyl composition of PG (14:0/16:0). For LPG, the same fragmentation was observed, with the exception that only one product ion corresponding to a fatty acid was detected.

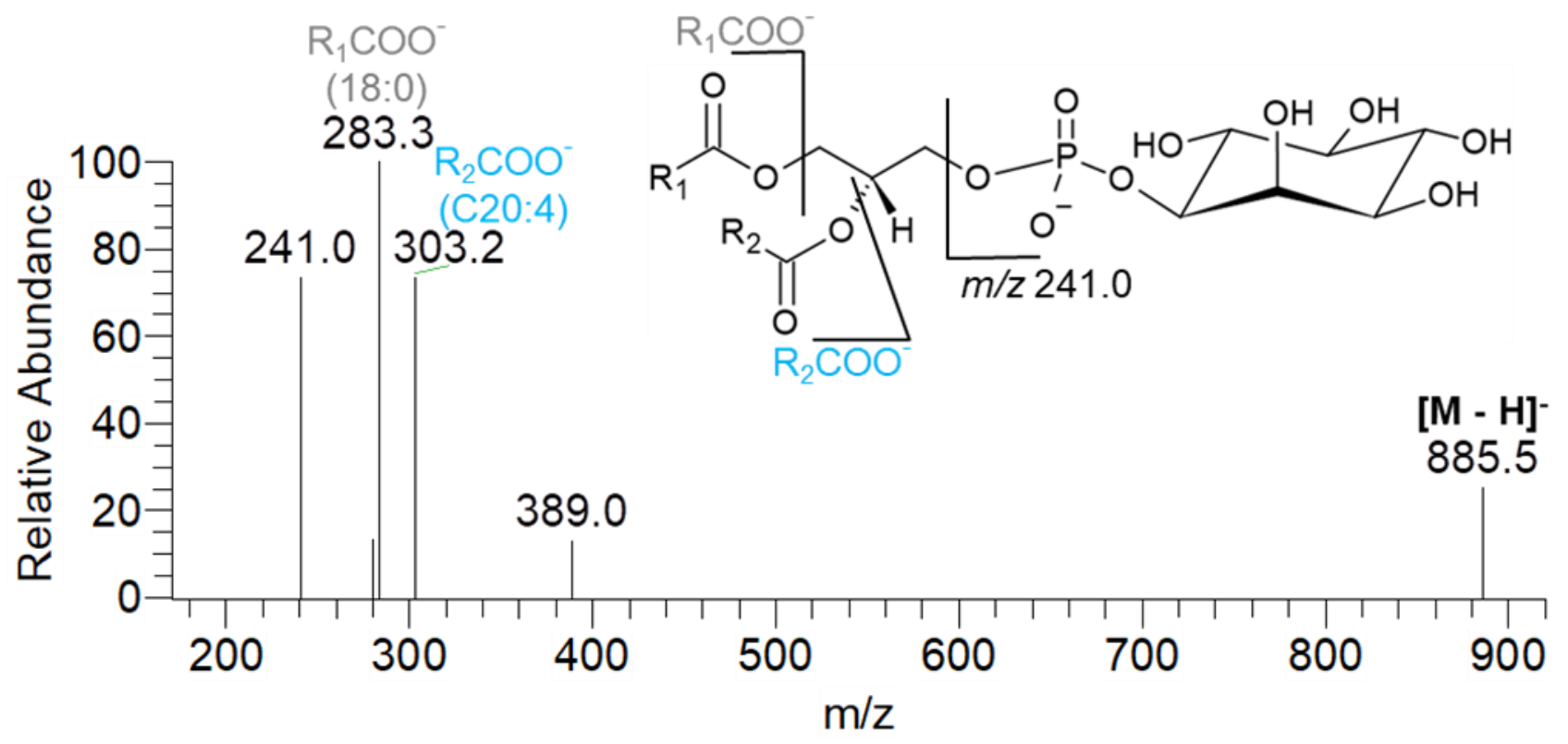

Supplementary Figure S6. Representative MS/MS spectrum of phosphatidylglycerol (PI) lipid species. HILIC-MS/MS spectrum of the lipid species $\mathrm{PI}(38: 4)$ observed in positive mode as $\left[\mathrm{M}-\mathrm{H}^{-}\right.$ion at $\mathrm{m} / \mathrm{z} 885.5$. Confirmation of phospholipid class was achieved by the identification of the product ion at $m / z 241.0$ (formula: $\mathrm{C}_{6} \mathrm{H}_{10} \mathrm{O}_{8} \mathrm{P}$; exact mass: 241.0113), corresponding to the phosphoinositol head group. Fatty acid composition was confirmed by the identification of product ions corresponding to the fatty acyl chains as [RCOO]. The product ions observed at $\mathrm{m} / \mathrm{z} 283.3$ and 303.2 , corresponding to fatty acyl carboxylate anions of 18:0 ( $\left.\mathrm{R}_{1} \mathrm{COO}^{-}\right)$and 20:4 ( $\left.\mathrm{R}_{2} \mathrm{COO}^{-}\right)$allowed to identify the fatty acyl composition of PI (18:0/20:4). 


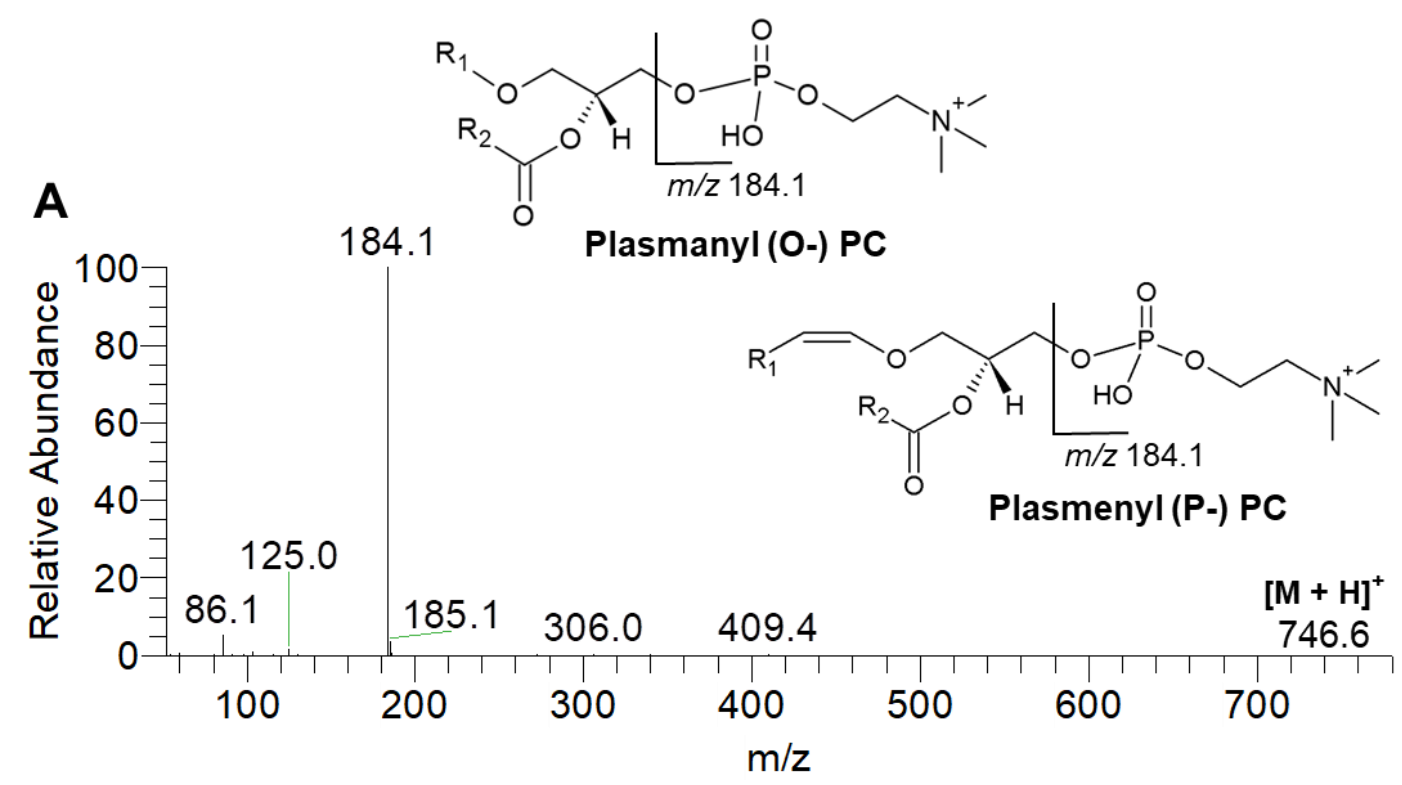<smiles>[R]OC[C@H](COP(=O)([O-])OCC[N+](C)(C)C(C)=O)[C@H](OC([R6])=O)C(=O)O</smiles>

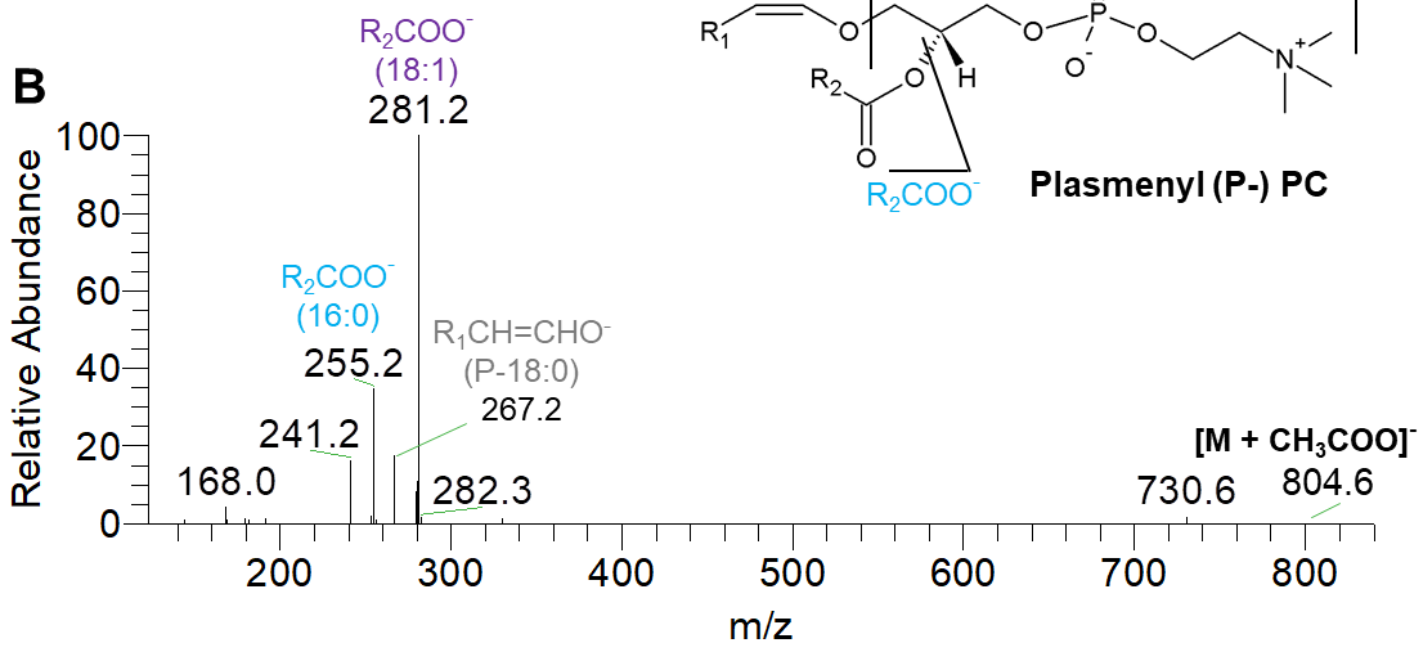

Supplementary Figure S7. Representative MS/MS spectra of isomeric plasmanyl (O-) and plasmenyl (P-) phosphatidylcholine (PC) lipid species, eluting at the same retention time in LC-MS. A) HILIC-MS/MS spectrum of the lipid species $\mathrm{PC}(\mathrm{O}-34: 1) / \mathrm{PC}(\mathrm{P}-34: 0)$ observed in positive mode as $[\mathrm{M}+\mathrm{H}]^{+}$ion at $\mathrm{m} / \mathrm{z} 746.6$. Confirmation of phospholipid class was achieved by the identification of the product ion at $\mathrm{m} / \mathrm{z} 184.1$ (formula: $\mathrm{C}_{5} \mathrm{H}_{15} \mathrm{NO}_{4} \mathrm{P}$; exact mass: 184.0739), corresponding to the phosphocholine polar head. B) HILIC-MS/MS spectrum of the lipid species $\mathrm{PC}(\mathrm{O}-34: 1) / \mathrm{PC}(\mathrm{P}-34: 0)$ observed in negative mode as $\left[\mathrm{M}+\mathrm{CH}_{3} \mathrm{COO}\right]^{-}$at $\mathrm{m} / z$ 804.6. For plasmenyl ( $\mathrm{P}-$ ) species, fatty acid composition was confirmed by the identification of a product ion corresponding to the esterlinked fatty acid as [RCOO] ${ }^{-}$and, in some cases (not visible from molecular ions with low intensity), of another product ion corresponding to the ether-linked fatty acid as $[\mathrm{RCH}=\mathrm{CHO}]$. Plasmanyl $(\mathrm{O}-)$ species yielded only a product ion corresponding to the ester-linked fatty acid as [RCOO]- In the case of the lipid species PC(O34:1)/PC(P-34:0), three possible molecular lipid species with distinct fatty acyl composition were identified. The product ions observed at $\mathrm{m} / \mathrm{z} 267.2(283-16)$ and 255.2, corresponding to $\mathrm{P}-18: 0\left(\mathrm{R}_{1} \mathrm{CH}=\mathrm{CHO}^{-}\right)$and 16:0 $\left(\mathrm{R}_{2} \mathrm{COO}^{-}\right)$, allowed to identify the fatty acyl composition of $\mathrm{PC}(\mathrm{P}-18: 0 / 16: 0)$. The product ion observed at $\mathrm{m} / \mathrm{z}$ 281.2 , corresponding to fatty acyl carboxylate anion of $18: 1\left(\mathrm{R}_{2} \mathrm{COO}^{-}\right)$, allowed to infer the presence of $\mathrm{PC}(\mathrm{O}$ 16:0/18:1). Also, the presence of PC(O-18:1/16:0) cannot be excluded, as it may contribute for the observation of the product ion at $\mathrm{m} / \mathrm{z} 255.2$, corresponding to fatty acyl carboxylate anion of $16: 0\left(\mathrm{R}_{2} \mathrm{COO}^{-}\right)$. 
A
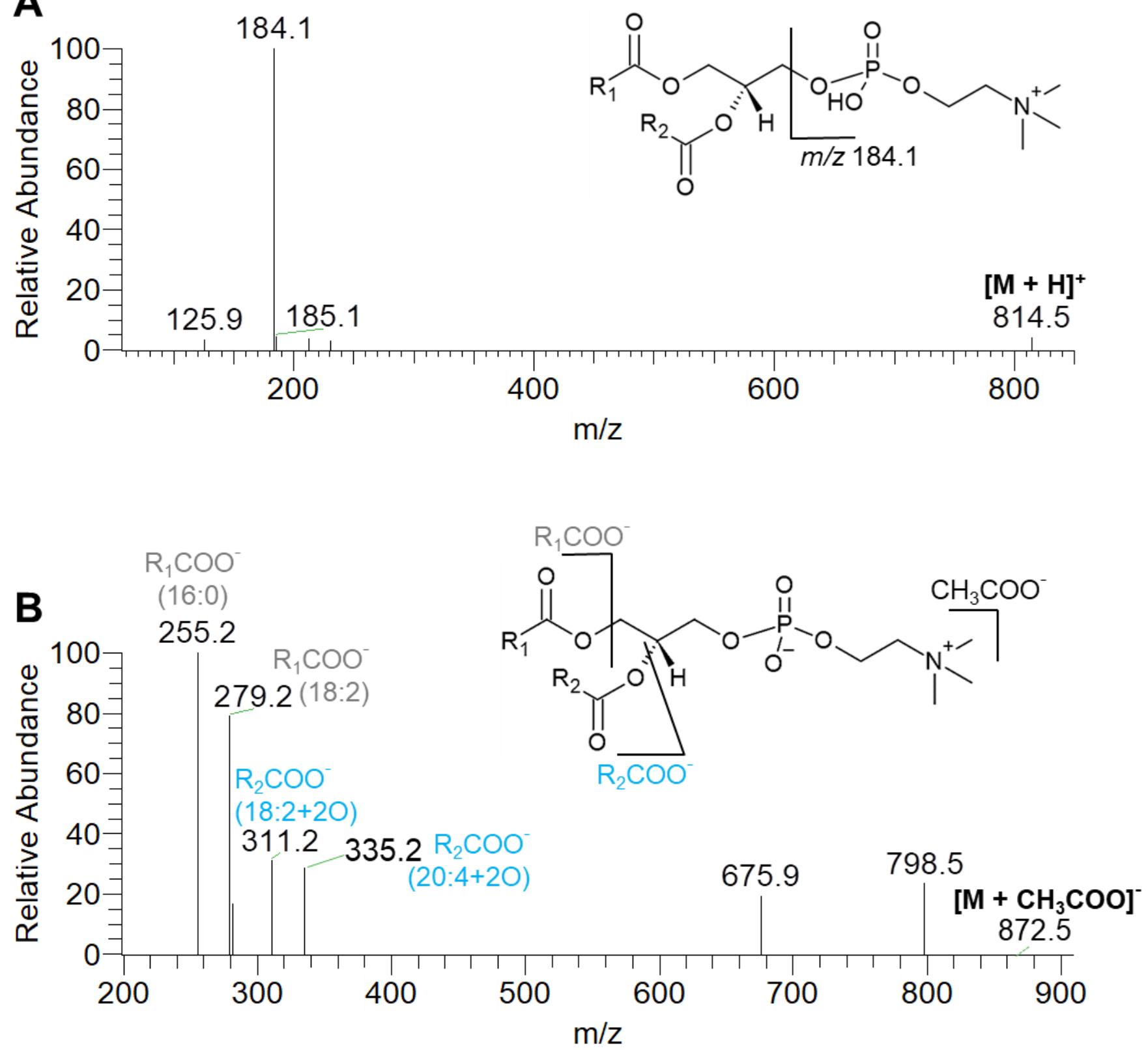

Supplementary Figure S8. Representative MS/MS spectra of oxidized phosphatidylcholine (PC) lipid species. A) HILIC-MS/MS spectrum of the lipid species PC $(36: 4)+2 \mathrm{O}$ observed in positive mode as $[\mathrm{M}+\mathrm{H}]^{+}$ion at $\mathrm{m} / z$ 814.5. Confirmation of phospholipid class was achieved by the identification of the product ion at $\mathrm{m} / \mathrm{z} 184.1$ (formula: C5H15NO4P; exact mass: 184.0739), corresponding to the phosphocholine polar head. B) HILIC-MS/MS spectrum of the lipid species PC (36:4)+2O observed in negative mode as [M + $\left.\mathrm{CH}_{3} \mathrm{COO}\right]^{-}$at $\mathrm{m} / \mathrm{z}$ 872.5. Fatty acid composition was confirmed by the identification of product ions corresponding to the fatty acyl chains as [RCOO]'. In this case, two molecular lipid species with distinct fatty acyl composition were identified. The product ions observed at $\mathrm{m} / \mathrm{z} 255.2$ and 335.2 , corresponding to fatty acyl carboxylate anions 16:0 ( $\left.\mathrm{R}_{1} \mathrm{COO}^{-}\right)$and $20: 4+2 \mathrm{O}\left(\mathrm{R}_{2} \mathrm{COO}^{-}\right)$allowed to identify the fatty acyl composition of PC (16:0/20:4+2O). The product ions observed at $\mathrm{m} / \mathrm{z} 279.2$ and 311.2 , corresponding to fatty acyl carboxylate anions 18:2 ( $\left.\mathrm{R}_{1} \mathrm{COO}^{-}\right)$and 18:2+2O ( $\left.\mathrm{R}_{2} \mathrm{COO}^{-}\right)$allowed to identify the fatty acyl composition of PC (18:2/18:2+2O). For LPC, the same fragmentation was observed, with the exception that only one product ion corresponding to a fatty acid was detected. 